\title{
Heavy Metal Contaminations in Herbal Medicines: Determination, Comprehensive Risk Assessments, and Solutions
}

Lu Luo

China Academy of Chinese Medical Sciences https://orcid.org/0000-0002-5601-0801

Bo Wang

Hubei Institute for Drug Control, China

Jingwen Jiang

Sichuan University West China Hospital

Qin Huang

China Academy of Chinese Medical Sciences

\section{Zheng Yu}

Chengdu University of Traditional Chinese Medicine

Hui Li

Chinese Academy of Sciences

Jiqing Zhang

China Academy of Chinese Medical Sciences

Chenyuyan Yang

Chinese Academy of Medical Sciences

Hui Zhang

Akupunktur Akademiet

Linlin Dong

China Academy of Chinese Medical Sciences

Shilin Chen ( $\nabla$ slchen@icmm.ac.cn )

China Academy of Chinese Medical Sciences https://orcid.org/0000-0002-0449-236X

\section{Research}

Keywords: heavy metal, herbal medicine, extrinsic contamination, risk assessment

Posted Date: August 7th, 2020

DOI: https://doi.org/10.21203/rs.3.rs-53256/v1 
License: (c) (i) This work is licensed under a Creative Commons Attribution 4.0 International License. Read Full License

Version of Record: A version of this preprint was published at Frontiers in Pharmacology on January 14th, 2021. See the published version at https://doi.org/10.3389/fphar.2020.595335. 
1 Heavy Metal Contaminations in Herbal Medicines: Determination,

2 Comprehensive Risk Assessments, and Solutions

3 Lu Luo $^{1 \dagger}$, Bo Wang ${ }^{2 \dagger}$, Jingwen Jiang ${ }^{3}$, Qin Huang ${ }^{1}$, Zheng $\mathrm{Yu}^{4}$, Hui $\mathrm{Li}^{5}$, Jiqing Zhang ${ }^{1}$, Chenyuyan

$4 \quad$ Yang $^{6}$, Hui Zhang ${ }^{7}$, Linlin Dong ${ }^{1 *}$, Shilin Chen ${ }^{1 *}$

5 *Correspondence to: Prof Lilin Dong and Shilin Chen, Institute of Chinese Materia Medica, China

6 Academy of Chinese Medical Sciences, Beijing 100700, China

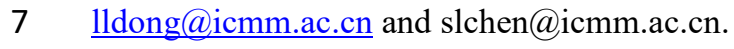

8

9

\section{Abstract}

Background: Heavy metal contamination in herbal medicines is a global threat to human beings especially at levels above known threshold concentrations.

Methods: The concentrations of five heavy metals cadmium $(\mathrm{Cd})$, lead $(\mathrm{Pb})$, arsenic $(\mathrm{As})$, mercury $(\mathrm{Hg})$ and copper $(\mathrm{Cu})$ were investigated using Inductively Coupled Plasma Optical Mass Spectrometry (ICP-MS) with 1773 samples. Exposure assessment, Non-carcinogenic risk assessment, and carcinogenic risk assessment were applied to measure their risks in human body.

Results: According to Chinese Pharmacopoeia, 30.51\% (541) samples were detected with at least one over-limit metal. The over-limit ratio for $\mathrm{Pb}$ was $5.75 \%$ (102), Cd at 4.96\% (88), As at 4.17\% (74), $\mathrm{Hg}$ at $3.78 \%$ (67), and of $\mathrm{Cu}, 1.75 \%$ (31). For exposure assessment, $\mathrm{Pb}, \mathrm{Cd}, \mathrm{As}$, and $\mathrm{Hg}$ have resulted in higher than acceptable risks in 25 kinds of herbs. The maximal Estimated Daily Intake (EDI) of Pb in seven herbs, of $\mathrm{Cd}$ in five, of $\mathrm{Hg}$ in four, and $\mathrm{As}$ in three exceeded their corresponding Provisional Tolerable Daily Intakes (PTDI). In total 25 kinds of herbs present an unacceptable risk as assessed with the HQ (Hazard Quotient) or HI (Hazard Index). Particularly, Plantaginis herba $(\mathrm{HI}=11.47)$ is more 
than 11 times over the limit.

Conclusions: Heavy metal contamination in herbal medicines was borderline or higher than the safety level with the majority of the herbal plants were within acceptable risks. Notably, As posed the highest risk in all indicators including EDI, HI, and CR, inducing the most serious risks in all five metals. Herbal medicines Euodiae fructus, Plantaginis herba, and Desmodii styracifolii were considered the most risk-inducing herbal medicines. Therefore, it is of great advantage to establish universal standards and quality requirements for hazardous elements in herbal medicines so that this natural resource can continue and expand further, to benefit health globally.

Key words: heavy metal; herbal medicine; extrinsic contamination; risk assessment

\section{Background}

Having been utilized as traditional folk remedies for thousands of years [1], medicinal plants gained an increasingly important role in the pharmaceutical, health food, and natural cosmetic industries[2]. It was reported that a total of 60,107 COVID-19 cases $(85.20 \%$ of the total cases) in China were treated by Chinese herbal medicines with positive results in all infection stages, including significant symptom management, lower rates of deterioration and mortality, faster recovery as well as disease prevention on 17 February 2020 [3]. Over years, however, concerns grew regarding the safety of herbal medicines after studies indicated that high levels of heavy metals were present in some herbal medicines. This was a problem more frequently encountered in traditional medical therapy, considered to be a cause of several health disorders [1]. Samples taken from both 
developed and developing countries have shown high levels of potentially toxic heavy metals in products available to the public [4]. It is known that numerous traditional medicines can give rise to severe adverse renal pathology, the mechanism of which is yet not fully certain but has been associated with heavy metal toxicity [4]. Uptake of heavy metals by plants and subsequent accumulation along the food chain is a potential threat to animal and human health. Particularly as heavy metals are known to have low renal excretion rates, potentially resulting adverse effects in humans even at very low concentrations. They are not easily metabolized by body and are found to accumulate in the soft tissues. They produce toxic effects due to their interference in many know normal biochemical and metabolic processes [5]. Several health problems were linked to excessive uptake of dietary heavy metals, including decreased; immunity, cardiac dysfunction, fetal malformation, impaired psychosocial and neurological behavior [6]. $\mathrm{Pb}$ and $\mathrm{Cd}$ are not essential elements that are required neither in the human body nor in plants, and which cause various bimolecular adverse functional effects at low level doses [1]. Though an essential component of many enzymes, excessive intake of $\mathrm{Cu}$ can cause dermatitis, irritation of the upper respiratory tract, abdominal pain, nausea, diarrhea, vomiting, and liver damage [6]. While As and $\mathrm{Hg}$ can damage pulmonary, nervous, renal and respiratory systems, as well as causing skin pathology [7]. It may also induce disorders in the central nervous system, liver, lungs, heart, kidney and brain. Leading to hypertension, abdominal pain, skin eruptions, intestinal ulcer and is associated with various types of cancers [8]. It is therefore necessary and a matter of urgency to conduct a comprehensive risk assessment of heavy metal contamination in herbal medicines. 
contamination in herbal medicines have been carried out in China [9], India [10], Iran [11], Egypt [12], South Africa [13], United States [6], Brazil [14], and Australia [2], etc. Though a number of studies have been conducted regarding heavy metal contamination in herbal plants, most were with limited sample numbers and categories. Given the severe consequence it may bring to health and environment, exposure risk assessment [15], hazard quotient [9], and ecological risk assessment [4], have been conducted by researchers, showing that heavy metal contamination in herbal medicines is an area requiring immediate attention, with potential risk to human health having now being demonstrated. Though studies now show that exposure of heavy metals through general dietary consumption contribute negatively to human health [16], very few have conducted comprehensive health risk assessments, with large sample numbers focusing on herbal medicines. Furthermore, specific identification of metals is required for accurate diagnosis due to considerable overlap between various clinical syndromes associated with heavy metal poisoning [5]. Therefore a study of accurately quantified heavy metal contents in herbal medicines appears necessary to further assess and justify of the dosage of herbal formulas. This study assesses contamination levels and the health risk to humans posed by heavy metals more specifically in herbal medicines, providing an evidence base on which to further build prevention measures, establish relative standards, and control external contamination. Through investigation and suggested recommendations in able to significantly reduce or eliminate the levels of heavy metals in herbal medicines. 
A total of 1773 samples from 2014 to 2019, representing 86 different kinds of commonly used herbal medicines were collected for examination of heavy metals. As a part of a heavy metal detection project for Chinese Pharmacopoeia (2020 edition) [17] and based on the principle that only herbal medicines from large-scale production areas would be considered, at least three samples for each herbal medicine were collected from one to 13 different sampling locations. Sampling locations were chosen according to areas of traditional production of the herbal medicines, without regard to possible pollution sources. Duplicate specimens were taken from each same herbal medicine sample and every specimen was tested three times and the final mean concentration was adopted for further data analysis. Each bulk sample was harvested, cleaned, and processed according to the method required by Chinese Pharmacopoeia [17]. Precisely $0.5 \mathrm{~g}$ sample Electronic balance (Mettler Toledo) was first ground into powder, then soaked in polytetra fluoroethylene (PTFE) tank with $6 \mathrm{ml}$ nitric acid $\left(\mathrm{HNO}_{3}\right)$ added overnight. It was then predigested for one hour on a temperature controlled electronic hotplate with 1 $\mathrm{mL}$ hydrogen peroxide solution $\left(\mathrm{H}_{2} \mathrm{O}_{2}\right)$ added. After cooling down, more $\mathrm{HNO}_{3}$ was added to up to volume of $7 \mathrm{~mL}$. The PTFE tank was then placed in Multiwave PRO Microwave Digestion Apparatus (Anton Paar) for further digestion before being placed on a $130^{\circ} \mathrm{C}$ electronic hotplate, until reduced to 1 $\mathrm{mL}$. The tank was then removed for cooling and $50 \mathrm{~mL}$ of the digested liquid transferred to a graduated flask. The tank was flushed with low volume amounts of water multiple times and the complete washings added to the graduated flask, $200 \mu \mathrm{L}$ of single-element standard solution $\left(1 \mathrm{mg} \cdot \mathrm{L}^{-1}\right)$ was added. Then diluted up to the mark of the graduated flask with water, shaken and set aside. The blank solution was prepared in the same way except that no standard solution of single element and sample powder were added [18]. 
111 The resulting digestate was analyzed using a Scientific X Series Inductively-Coupled Plasma Mass

112 Spectrometer (ICP-MS) (Thermo Fisher Scientific, Waltham, MA). Heavy metal results from the

113 ICP-MS were quantified against standard curves generated from 1 blank and at least 4 standard

114 reference solutions (High-Purity Standards, Charleston, SC) run separately. Quality control was

115 assessed by running a laboratory reagent blank after every 10 samples. The limit of detection (LOD)

116 achieved for each metal was $0.1 \mathrm{mg} \cdot \mathrm{kg}^{-1}$ for $\mathrm{Cu}, 0.01 \mathrm{mg} \cdot \mathrm{kg}^{-1}$ for $\mathrm{As}, 0.005 \mathrm{mg} \cdot \mathrm{kg}^{-1}$ for $\mathrm{Cd}, 0.001$

$117 \mathrm{mg} \cdot \mathrm{kg}^{-1}$ for $\mathrm{Hg}$, and $0.01 \mathrm{mg} \cdot \mathrm{kg}^{-1}$ for $\mathrm{Pb}$. The detection limit was based on consideration of the blank

118 runs, concentration of the low standard in the calibration curve and the sample preparation procedure.

119 Based on this method, the limit of detection was considered equivalent to the limit of quantification $120 \quad[19-20]$.

121 In our experiment, standard solutions of $\mathrm{Cu}\left(\mathrm{GSB} 04-1725,1000 \mathrm{mg} \cdot \mathrm{L}^{-1}\right)$, As (GSB04-1714, 1000

$\left.122 \mathrm{mg} \cdot \mathrm{L}^{-1}\right), \mathrm{Cd}\left(\mathrm{GSB} 04-1721,1000 \mathrm{mg} \cdot \mathrm{L}^{-1}\right), \mathrm{Hg}(\mathrm{GSB} 04-1729,1000 \mathrm{mg} \cdot \mathrm{L}), \mathrm{Pb}(\mathrm{GSB} 04-1742,1000$

$123 \mathrm{mg} \cdot \mathrm{L}^{-1}$ ) were purchased from the National Nonferrous Metals and Electronic Materials Analysis and

124 Testing Center, while Analytical Reagents (AR) nitric acid $\left(\mathrm{HNO}_{3}\right)$ and hydrofluoric acid (HF) were

125 purchased from Merck Co., Ltd., and guaranteed reagents (GR) hydrogen peroxide and hydrochloric

126 acid from Sinopharm Chemical Reagent Co., Ltd. Each single-element standard solution was measured

127 precisely and then diluted with $5 \% \mathrm{HNO}_{3}$ to make a mixed solution containing $1 \mu \mathrm{g} \mathrm{mL}^{-1}$. For a

128 reference stock solution, single-element standard solutions of the five metals were separately taken and

129 diluted with $5 \%$ nitric acid to make solutions containing $5 \mu \mathrm{g}$ of $\mathrm{Pb}$ and $\mathrm{As}, 50 \mu \mathrm{g}$ of $\mathrm{Cu}, 2.5 \mu \mathrm{g}$ of $\mathrm{Cd}$,

130 and $0.5 \mu \mathrm{g}$ of $\mathrm{Hg}$. For preparation of a reference standard curve, precise measurement were taken of the

131 above stock solution diluted with 5\% nitric acid to make standard mixtures with: $0,1,5,10,20$, and 50 
132

133

134

135

136

137

138

ng As or Pb per $1 \mathrm{~mL}$; 0, 10, 50, 100, 200, and $500 \mathrm{ng} \mathrm{Cu}$ per $1 \mathrm{~mL}$; with 0, 0.5, 2.5, 5, 10, and $25 \mathrm{ng}$ Cd per $1 \mathrm{~mL}$; with $0,0.1,0.5,1,2$, and $5 \mathrm{ng} \mathrm{Hg}$ per $1 \mathrm{~mL}$ [6].

The conditions for Inductively coupled plasma mass spectrometry (ICP-MS) conditions were: Radio Frequency (RF) power: $1400 \mathrm{~W}$; sampling depth: $15 \mathrm{~mm}$; auxiliary gas (argon) flow rate: $0.8 \mathrm{~L} \mathrm{~min}^{-1}$; cooling gas flow rate: $13.0 \mathrm{~L} \mathrm{~min}^{-1}$; peristaltic pump speed: $30.0 \mathrm{~L} \mathrm{~min}^{-1}$; channel three; repeat for three times; scan for 100 times, automatic detection. Before samples were measured, the instrument was optimized to perform under the optimal conditions. Microwave digestion was set on a digestion program. For the first stage, $1100 \mathrm{~W}$, maintained for 10 minutes then further, for the second stage, 1400 W for 15 minutes and held for 20 minutes[21]. The detailed methodology is listed in the appendix (Table S1).

\section{Quantification of heavy metal contamination}

Mean concentrations, general detection rate, and detection rates of each metal were calculated. Figures were plotted using $R$ language [no IDE (integrated development environment), $R$ from the linux terminal $R$ version 3.5.1. (2018-007-02)--'Feather Spray" Copyright (C) 2018, the $R$ Function for Statistic Computing Platform: x86_64-pc-linux-gnu (64-bit)] [22].

\section{Over-limit ratio of five heavy metals}

In total, 27 currently available permissible limits containing five heavy metals were obtained from 20 countries or regions and seven international organizations (Table S2). The detailed calculation of both 
154

155

156

$170 \quad \mathrm{EDI}=\frac{\mathrm{C} \times \mathrm{IRD}}{\mathrm{BW}}$

general over-limit ratio and that of each metal in different producing areas were shown in supplementary material (Table S3). Herbal medicines were classified into five categories based on which part of the plant is employed for medicinal use: flos, folium \& cortex, fructus $\&$ semen, herba $\&$ others, and radix \& rhizome. Numbers of over-limit samples and metals were calculated from within across these five medicinal herbal properties.

Over-limit ratio $=(C-$ Limit $) \times 100 \%$

Times over permissible limit $=\frac{\text { C-Limit }}{\text { Limit }} \times 100 \%$

\section{Three health risk assessments of heavy metal contamination in herbal medicines}

Exposure assessment, non-carcinogenic risk assessment, and carcinogenic risk assessment were employed to explore the potential health impacts from heavy metal contamination in herbal medicines. The minimal, mean and maximal concentrations of each metal in each herbal medicine were applied for calculations with the equations below:

\section{Exposure assessment}

172 The estimated daily intake (EDI, $\left.\mathrm{mg} \cdot \mathrm{kg}^{-1} \cdot \mathrm{day}^{-1} \cdot \mathrm{bw}\right)$ of each metal in each sample was calculated, 
173 before comparison with its corresponding provisional tolerable daily intake (PTDI). The PTDIs

$174\left(\mathrm{mg} \cdot \mathrm{kg}^{-1} \cdot \mathrm{d}^{-1}\right)$ of $\mathrm{As}, \mathrm{Cu}, \mathrm{Hg}, \mathrm{Pb}$, and $\mathrm{Cd}$ are $0.00214,0.5,0.00057,0.00357$, and 0.00083 , respectively

175 [23]. $C$ in the equation here refers to the concentrations detected of each metal in herbal medicines

176 (maximal, mean and minimal concentrations were all considered). IRD refers to daily ingestion rate,

177 which signifies the daily dosage of herbal medicines. Here the maximal dosage specified in CP (2020

178 edition) was applied. BW is body weight, and average human weight of $60 \mathrm{~kg}$ was applied in the 179 equation[24].

180

181

Non-carcinogenic risk assessment

182

183 The non-cancer risk was evaluated by comparing an exposure level over a specified time period (e.g., lifetime) with a reference dose derived for a similar exposure period. The non-cancer risk can be characterized as a hazard quotient (HQ) [23].

IR is the daily dosage of herbal medicine, and according to a questionnaire on herbal medicine consumption of 20917 people, the $95^{\text {th }}$ percentile of daily dosage of general herbal medicine consumption is $0.5 \mathrm{~kg}$; Ef is exposure frequency, here the $95^{\text {th }}$ percentile of annual consumption on herbal medicine was adopted which was set 90 days per year; Ed is the exposed days over a lifetime which was set as 20 years; AT is the average lifetime $=365$ days $\times 70$ years, while $t$ is the transfer rate of 
195

198

199

200

201

202

203

204

205

refers to Oral reference dose $\left(\mathrm{mg}^{-1} \mathrm{~kg}^{-1}\right.$ day), which is 0.0035 for $\mathrm{Pb}, 0.0005$ for $\mathrm{Cd}, 0.0003$ for As, 0.0003 for $\mathrm{Hg}$ and 0.04 for $\mathrm{Cu}[26]$.

$\mathrm{HI}=\sum \mathrm{HQ}$

HQs of five heavy metals in each herbal medicine were summed up to obtain non-carcinogenic Hazard

Index (HI). If HQ or HI is less than 1, there will not be obvious risk for exposed population from metal exposure in herbal medicine. If $\mathrm{HQ}$ or $\mathrm{HI}$ is equal to or above 1, the risk will be considered unacceptable. As the HQ or HI increases, the risk also does. The contributions of HQs of each metal $\left(\mathrm{HQ}_{\mathrm{m}}\right)$ to the total $\mathrm{HI}$ were calculated to explore which metal contributed the most serious risks [27].

Contribution of $\mathrm{HQ}_{\mathrm{m}}$ to $\mathrm{HI}=(H Q m-H I) \times 100 \%$

\section{Carcinogenic risk assessment}

$\mathrm{CR}=\frac{\mathrm{C} \times \mathrm{IR} \times \mathrm{Ef} \times \mathrm{Ed} \times \mathrm{t} \times \mathrm{CSF}}{\mathrm{AT} \times \mathrm{BW} \times \mathrm{RfD}} \times 10^{-6}$

CSF ( $\left.\mathrm{mg} \cdot \mathrm{kg}^{-1} \cdot \mathrm{day}^{-1} \cdot \mathrm{bw}\right)$ is the cancer severity factor, only three heavy metals were proven with certain CSF: 6.1 for $\mathrm{Cd}, 1.5$ for As and 0.0085 for $\mathrm{Pb}$, while $10^{-6}$ is the conversion factor. $\mathrm{CR}$ of these three metals in the same herbal medicine was also summed up to give total CR of single herbal medicine. If CR is higher than $10^{-6}$, which means one case of cancer over one million exposed people, it is considered unacceptable [28]. 


\section{Results}

Heavy metals were detected in all 1773 samples. The order of detection rates of heavy metal plant properties are: for $\mathrm{Cu}$, flos $>$ herba $\&$ others $>$ folium $\&$ cortex $>$ radix $\&$ rhizoma $>$ fructus $\&$ semen; for As, herba \& others $>$ folium \& cortex $>$ flos $>$ radix \& rhizoma $>$ fructus $\&$ semen; for $\mathrm{Cd}$, semen $>$ herba $\&$ others $>$ folium $\&$ cortex $>$ radix $\&$ rhizoma; while for $\mathrm{Pb}$, herba $\&$ others $>$ folium $\&$ cortex $>$ flos $>$ radix $\&$ rhizoma $>$ fructus $\&$ semen (Fig.1). The highest concentration detected for $\mathrm{Cu}$ was in herbal medicine Schisandrae chinensis fructus $\left(34.01 \mathrm{mg} \cdot \mathrm{kg}^{-1}\right)$, the highest concentration of As was in Plantaginis herba $\left(14.53 \mathrm{mg} \cdot \mathrm{kg}^{-1}\right)$, of Cd was in Curcumae longae rhizome $\left(6.20 \mathrm{mg} \cdot \mathrm{kg}^{-1}\right)$, of conclusion, all five heavy metals were widely detected in herbal medicines, particularly, $\mathrm{Cu}$ and $\mathrm{Pb}$, most notably in flos and herba parts of medicinal plants.

In a total of 541 samples (30.51\%) were detected at levels over the CP (2020 edition) standard, and 433 
of five heavy metals based on $\mathrm{CP}(2020$ edition) standard is $\mathrm{Pb}(102,5.75 \%)>\mathrm{Cd}(88,4.96 \%)>\mathrm{As}$ $(74,4.17 \%)>\mathrm{Hg}(67,3.78 \%)>\mathrm{Cu}(31,1.75 \%)$. The times of highest concentration detected over the standards of $\mathrm{CP}$ (2020 edition) were 1.70 for $\mathrm{Cu}$ (Schisandrae chinensis fructus), 6.27 for As

For $\mathrm{Cu}(n=31)$, there are $12.90 \%$ samples detected over-limit in flos, $9.68 \%$ in folium \& cortex, $16.13 \%$ 
acceptable limit, the concentrations detected in all five heavy metals in few herbal medicines have surpassed their corresponding Provisional Tolerable Daily Intakes (PTDI), demonstrating unacceptable risk to health. The EDIs of three heavy metals $(\mathrm{Cd}, \mathrm{Hg}$, and $\mathrm{Pb})$ in Desmodii styracifolii herba have surpassed their corresponding PTDIs (Fig.3, Fig.S1, Table S4). Notably, a total of 12 herbal medicines out of 86 have presented with EDIs above their corresponding PTDIs. The maximal EDI of As in three herbal plants Plantaginis herba (0.007), Taraxaci herba (0.002), and Corni fructus (0.002); of Cd in five herbal plants Desmodii styracifolii herba (0.001) Andrographis herba (0.0008), Curcumae longae rhizoma (0.001), Lonicerae flos (0.001), and Houttuyniae herba (0.002), of $\mathrm{Hg}$ in four herbal plants Desmodii styracifolii herba (0.001), Chrysanthemi flos (0.001), Forsythiae fructus (0.001), and Euodiae fructus (0.001); and of $\mathrm{Pb}$ in seven herbal plants Plantaginis herba (0.024), Taraxaci herba (0.004), Desmodii styracifolii herba (0.008) Lonicerae flos (0.004), Houttuyniae herba (0.004), Euodiae fructus (0.004), Lonicerae japonicae flos (0.005) exceeded their corresponding PTDIs (Fig.3).

For non-carcinogenic risk, the majority of the herbal medicines were calculated with risks within the acceptable limit $(<1)$. The HIs of a total of 86 herbal medicines ranged from 11.47 (Plantaginis Herba) and 0.02 (Chaenomelis Fructus) and HIs in a total of 25 out of 86 kinds of herbal medicines (29.07\%) showed values over 1, thus considered unacceptable risk. HQs of As in 20 herbal medicines, of $\mathrm{Hg}$ in five herbal medicines, of $\mathrm{Pb}$ in two herbal medicines, and of $\mathrm{Cd}$ in one herbal medicine exceeded 1 , considering as unacceptable risks. It was also shown that heavy metal As contributed the most in $\mathrm{HQ}>1$ herbal medicines (The highest was $92.94 \%$ in Corni Fructus). Heavy metal As has shown the highest non-carcinogenic $(\mathrm{HQ}=9.95)$, presenting more severe risks than other four heavy metals (Fig.3, Table 2, Fig. S2, Table S4). 
283 For carcinogenic risks, all CRs were found to be within the acceptable limit $\left(10^{-4}\right)$ [29]. The highest 284 risk of As was found in Plantaginis herba (4.48E-09), the lowest was in Ziziphi spinosae semen 285 (3.12E-12); the highest of Cd was in Curcumae longae rhizome (3.11E-09), the lowest in Citri grandis exocarpium (2.51E-12); and the highest of $\mathrm{Pb}$ was in Euodiae fructus (3.50E-11), the lowest were in Puerariae lobatae radix and Ziziphi spinosae semen (6.99E-15). Andrographis herba presented with the highest total carcinogenic risk (5.27E-09), while Ziziphi spinosae semen the lowest (5.83E-12). Among these top risk-inducing herbs, nine belong to fructus \& semen (Fig.4). Heavy metal As has shown carcinogenic risks $(\mathrm{CR}=4.48 \mathrm{E}-09)$, which, again, presented with the highest carcinogenic risk.

In total here, $25(29.07 \%)$ different kinds of herbal medicines $(n=86)$, presented with unacceptable risks based on exposure assessment, among which, nine belonged to fructus \& semen, six belonged to herba $\&$ others, five belonged to the flos category, three belonged to radix \& rhizoma, and two belonged to the folium \& cortex. Plantaginis herba presented with the highest non-carcinogenic risk $(\mathrm{HI}=11.47)$, while Andrographis herba with the highest carcinogenic risk $(\mathrm{CR}=5.27 \mathrm{E}-09)$. Heavy metal As has shown both the highest non-carcinogenic $(\mathrm{HQ}=9.95)$ and carcinogenic risks $(\mathrm{CR}=4.48 \mathrm{E}-09)$ in herbal medicines. As these particular herbal medicines and heavy metals have the potential to cause health problems, they are in need of special monitoring to reduce potential risk (Table 2).

\section{Discussion}

Based on this study with a large-spatio-temporal-scale herbal medicine samples, 30.51\% (541) of 
303

samples were detected with at least one over-limit heavy metal. Five heavy metals (As, $\mathrm{Pb}, \mathrm{Cu}, \mathrm{Hg}$ and $\mathrm{Cd}$ ) were widely detected in cultivated herbal medicines according to our experiment, which is in accordance with other published results [30-31]. In Nigerian herbal remedies, $100 \%$ of the samples also contained elevated amounts of heavy metals [32], which revealed that the Nigerian herbs contained high levels of $\mathrm{Fe}, \mathrm{Ni}, \mathrm{Cd}, \mathrm{Cu}, \mathrm{Pb}$, Se, and $\mathrm{Zn}$ sufficient to cause adverse health effect when regularly taken as recommended. In our study, 27 (31.40\%) different kinds of herbal medicines, mostly with fructus \& semen part with medicinal applications posed unacceptable health risk due to heavy metal accumulation though herba \& others were detected with the highest over-limit ratio. Toxic element As posed the most serious health risk according to exposure, carcinogenic and non-carcinogenic risk assessments, as health risk assessment employed by Ren, indicated that $\mathrm{As}$ and $\mathrm{Pb}$ generated from industrial sites and traffic sites has a potential to pose serious health risks [33]. It was also found that As was the major metal found for water pollution [29], exceeding its permitted daily exposure dosages and suggested a potential health risk for $P$. notoginseng consumers [34]. Considering that the content of As detected is total As and As exists in different states. The toxicity of As in different states varies tremendously. Both organic and inorganic As exist in the soil, while the states of As may transform in biological activities both in plants and human metabolism. So it is hard to say if high concentration of total As would absolutely harm human health. However, As is certainly necessitating special attention and further study on its state transformation. Furthermore, Bolan employed a study and asserted that the concentrations of $\mathrm{Cd}, \mathrm{Hg}$, and $\mathrm{Pb}$ in Ayurvedic medicines exceeded their daily intake amounts [35]. According to the study by Lee SD, levels of Cd exceeding WHO reference values were observed in 10 samples and the weekly intakes of $\mathrm{Pb}, \mathrm{Cd}, \mathrm{Cr}, \mathrm{Cu}, \mathrm{Hg}$ from herbs [36]. While in Iran, 
maximum bioaccumulate of $\mathrm{Pb}$ and $\mathrm{Hg}$ was noted in Artemisia dracunculus $\mathrm{L}$ and Spinacia oleracea L, respectively [37]. The non-carcinogenic risks target hazard quotients (THQs) of Al and $\mathrm{Cr}$ from individual herbs were over 1, which might impart risk for human consumption. It could be concluded that heavy metals $\mathrm{As}, \mathrm{Pb}, \mathrm{Cd}$, and $\mathrm{Hg}$ all impose significant risk to health due to herbal consumption. The highest HI was presented in herbal medicine Plantaginis Herba $(\mathrm{HI}=11.47)$ and highest $\mathrm{CR}$ in Andrographis herba $(\mathrm{CR}=5.27 \mathrm{E}-09)$, which are in need of special dosage control and monitoring. Furthermore, the highest over-limit ratios of five heavy metals based on different producing areas are $\mathrm{Cu}(7.69 \%)$ in Chongqing, As (20.21\%) in Gansu province, $\mathrm{Cd}(0.77 \%)$ in Chongqing, $\mathrm{Hg}(9.89 \%)$ in Hunan province, and $\mathrm{Pb}(25.00 \%)$ in Fujian province (Tables S3). However, Principle Components Analysis (PCA) didn't showcase that there was significant statistic difference regarding the five heavy mental accumulations in five medicinal plant properties. While according to Pearson Correlation Analysis, $\mathrm{Pb}$ and As were correlated to flos, folium \& cortex, fructus \& semen, and herba \& others, while $\mathrm{Pb}$ and $\mathrm{Cd}$ in radix \& rhizoma (Fig.S3, 4). Additionally, based on the Analysis of Similarities (ANOSIM), it was indicated that the difference within groups of five medicinal plant properties is less significant than the one throughout the five groups (R=0.165, $P=0.001$ ) (Fig.S5).

Generally, five reasons explain the levels of heavy metal contents in herbal medicines. The first is the variable exposure to environmental pollution including industrial encroachment, contaminated soil or atmosphere. The physicochemical properties of soil including $\mathrm{pH}$, temperature, redox potential, translocation exchange capacity and organic matter may influence the availability of metal to plants. Secondly, the phytological characteristics of medical plants themselves such as reduced biomass, root 
347 length and shoot length are common indicators of heavy metal toxicity. Furthermore, the interactions of

348 soil-plant roots-microbes play vital roles in regulating heavy metal movement from the soil to edible

349 plant parts. Certain plants are "hyper-accumulators" which grow on metalliferous soils and accumulate

350 extraordinarily high levels of heavy metals without displaying phytotoxic effects. Thirdly, herbal plants

351 could be contaminated during manufacturing and agronomic processes [38] including growing,

352 harvesting, transportation, processing and storage, due to pesticide formulations, chemical fertilizers

353 and irrigation with poor-quality water [6,35]. For example, $\mathrm{Cd}$ and $\mathrm{Pb}$ may enter the soil due to

354 fertilizer impurities [39], non-ferrous smelters, lead and zinc mines, sewage slug application and

355 combustion of fossil fuels [40]. Additionally, fumigants containing heavy metals may also be applied

356 for preventing rats and mildew [41]. Fourthly, plant uptake is one of the major routes of dietary

357 exposure to heavy metals in the soil, and the wide variations in metal concentrations in the analyzed

358 herbs could be attributed to differences in the plant metal uptake and translocation capabilities. Studies

359 have shown wide variations in concentration factor for different metals among different plant species

360 and sampling sites. Certain species have higher tendency to accumulate Cd [6]. Lastly, the

361 bioavailability of heavy metals could have an impact on their concentrations, such as; soil $\mathrm{pH}$, the

362 metal levels already resident in the soil, the oxidation-reduction potential of the soil, and other

363 chemical and physical factors [6] (Table S5).

364 Here we propose a solution for heavy metal control in herbal medicines. We consider, given the results

365 found here and those of others previously there is an urgent need to implement a regular monitoring

366 and surveillance program, controlling extrinsic contamination of herbal medicines along the supply

367 chain from field to consumer [35]. Secondly, research, such as identifying ways in which heavy metals

368 reach herbal products; development and validation of kinetic models linking processing techniques 
with metal speciation and bioavailability; bioavailability tests of heavy metals in herbal medicines; experiments on regression relationships between speciation and bioavailability of heavy metals, clinical studies examining the toxicity of heavy metals, etc. [6]. Soil amendments, including mitigation and preservation management for the growth performance of biomass and metal accumulation in contaminated soils, is necessary [2]. Lastly, tolerant medicinal plants with high phytoremediation potential and capability for phytostabilization and phytoextraction [2] can be cultivated as an approach for the management and targeted bio-extraction of heavy metals from moderately polluted lands [28], together with a combination of different agents such as $\mathrm{pH}$ change-inducing chemical immobilization, alkaline materials including lime based materials, fly ash, and biochar, calcite, dolomite, oyster and egg shell [2]. Sorption agents such as phosphate materials, compost, zeolite and iron compounds, activated carbon, and bentonite, or materials that decrease dissolved organic carbon (DOC) such as gypsum treatment, Solanum nigrum, microbes, chelating agents, Extracellular polysaccharides or Exopolysaccharides (EPS) [42], and eco-friendly biocarbon technology [43]. These materials increase soil $\mathrm{pH}$, favor deprotonation and the formation of oxides, metal-carbonate precipitates, complexes and secondary minerals that all decrease the phytoavailable heavy metal concentrations [1]. Phytoremediation has been perceived to be a more low-cost, low-impact, low-tech alternative, visually benign and environmentally sound comparing to more active and intrusive remedial methods [43] (Fig.5).

\section{Conclusion}

In conclusion, heavy metal contamination in herbal medicines was borderline or higher than the safety level. There are $30.51 \%$ samples detected with at least one over-limit heavy metal according to Chinese 
391

392

393

394

395

396

397

Pharmacopoeia (CP, 2020 edition) standards [17]. The risk assessments have demonstrated that the majority $(70.93 \%)$ of the herbal plants were within acceptable risks. Notably, As posed the highest risk in all indicators including EDI, HI, and CR, inducing the most serious risks in all five metals. Herbal medicines Euodiae fructus, Plantaginis herba, and Desmodii styracifolii were considered the most risk-inducing herbal medicines. Extrinsic contamination in herbal medicines is well demonstrated and clearly poses a serious potential risk to health. Furthermore, trace metals play a significant role in reactions which lead to formation of the active chemical plant constituents and are, therefore, responsible in-part for their curative as well as toxic properties. The analysis of toxic metals can be useful to evaluate the dosage of the herbal drugs prepared from these plants. Therefore, it is of great advantage to establish universal standards and quality requirements for hazardous elements in herbal medicines so that this natural resource can continue and expand further, to benefit health globally.

Additional file 1: Table S1.1 Methodological verification of ICP-MS for determination of five heavy metals in Menthae Haplocalycis Herba (18\#) herbal medicines $(\mathrm{n}=3)$. Table S1.2 Methodological verification of ICP-MS for determination of five heavy metals in Menthae Andrographis Herba (12\#) herbal medicines ( $\mathrm{n}=3$ ). Table S1.3 Methodological verification of ICP-MS for determination of five heavy metals in Menthae Isatidis Folium (14\#) herbal medicines (n=3). Table S1.4 Methodological verification of ICP-MS for determination of five heavy metals in Lycii Fructus (10\#) herbal medicines $(n=3)$. Table S1.5 Methodological verification of ICP-MS for determination of five heavy metals in Desmodii Styracifolii Herba (9\#) herbal medicines (n=3). Table S1.6 Methodological verification of ICP-MS for determination of five heavy metals in Carthami Flos (4\#) herbal medicines $(n=3)$. Table S1.7 Methodological verification of ICP-MS for determination of five heavy metals in Lonicerae 
Japonicae Flos (19\#) herbal medicines (n=3). Table S1.8 Methodological verification of ICP-MS for determination of five heavy metals in Chrysanthemi Flos (26\#) herbal medicines $(n=3)$. Table S1.9 Methodological verification of ICP-MS for determination of five heavy metals in Farfarae Flos (7\#) herbal medicines ( $n=3$ ). Table S1.10 Methodological verification of ICP-MS for determination of five heavy metals in Forsythiae Fructus (6\#) herbal medicines (n=3). Table S1.11 Methodological verification of ICP-MS for determination of five heavy metals in Chaenomelis Fructus (3\#) herbal medicines ( $\mathrm{n}=3$ ). Table S1.12 Methodological verification of ICP-MS for determination of five heavy metals in Ligustri Lucidi Fructus (2\#) herbal medicines (n=3). Table S1.13 Methodological verification of ICP-MS for determination of five heavy metals in Taraxaci Herba (27\#) herbal medicines $(n=3)$.

Table S1.14 Methodological verification of ICP-MS for determination of five heavy metals in Lonicerae Flos (13\#) herbal medicines (n=3). Table S1.15 Methodological verification of ICP-MS for determination of five heavy metals in Corni Fructus (16\#) herbal medicines $(n=3)$. Table S1.16 Methodological verification of ICP-MS for determination of five heavy metals in Ziziphi Spinosae Semen (1\#) herbal medicines ( $n=3)$. Table S1.17 Methodological verification of ICP-MS for determination of five heavy metals in Euodiae Fructus (8\#) herbal medicines $(n=3)$. Table S1.18 Methodological verification of ICP-MS for determination of five heavy metals in Schisandrae Chinensis Fructus (10\#) herbal medicines (n=3). Table S1.19 Methodological verification of ICP-MS for determination of five heavy metals in Houttuyniae Herba (2\#) herbal medicines ( $\mathrm{n}=3)$. Table S1.20 Methodological verification of ICP-MS for determination of five heavy metals in Gardeniae Fructus (14\#) herbal medicines ( $\mathrm{n}=3$ ). Table S1.21 Methodological verification of ICP-MS for determination of five heavy metals in Aurantii Fructus (4\#) herbal medicines ( $n=3$ ). Table S1.22 Methodological verification of ICP-MS for determination of five heavy metals in Perillae Folium (10\#) herbal 
medicines ( $\mathrm{n}=3$ ). Table S1.23 Methodological verification of ICP-MS for determination of five heavy metals in Plantaginis Herba (4\#) herbal medicines $(n=3)$. Table S2 Permissible limits of heavy metals in medicinal herbs (products) from different standards. Table S3 Over-limit ratio (\%) of five heavy metals in 32 producing areas. Table S4 The contributions of each metal in HI $>1$ herbal medicines. Table S5 Chronic and acute adverse effects of five heavy metals on health. Fig.S1. The over-limit Estimated Daily Intakes (EDI) of four heavy metals in herbal medicines. Fig.S2. The over-limit Hazard Quotients (HQ) of four heavy metals in 21 herbal medicines. Fig.S3.1 Spearman correlation coefficient of metal relations in flos. Fig.S3.2 Spearman correlation coefficient of metal relations in folium \& cortex. Fig.S3.3 Spearman correlation coefficient of metal relations in fructus \& semen. Fig.S3.4 Spearman correlation coefficient of metal relations in herba \& others. Fig.S3.5 Spearman correlation coefficient of metal relations in radix \& rhizoma. Fig.S4.1 Principle Components Analysis (PCA) of five heavy metal contents in five plant properties. Fig.S4.2 PCA of five heavy metals in 32 producing areas. Fig.S5 Analysis of Similarities (ANOSIM) of five heavy metal contents in five medicinal plant properties.

\section{Acknowledgements}

The authors thank Hubei Institute for Drug Control, China for conducting the heavy metal detection experiments.

\section{Authors' contributions}

Shilin Chen: Conceptualization and Supervision; Linlin Dong: Conceptualization, Methodology and Sample Collection; Lu Luo: Data analysis, Original Draft, Visualization, Review \& Editing. Bo Wang: 
457 Heavy Metal Analysis; Jingwen Jiang, Qin Huang, Jiqing Zhang and Chenyuyan Yang: Data analysis 458 and Visualization; Zheng Yu and Hui Li: Validation; Hui Zhang: Review \& Editing. All authors proved 459 the final text.

460

461

462

463

464

465

466

467

468

469

470

471

472

473

474

475 All authors declare no competing interests.

\section{Availability of data and materials}

\section{Consent for publication}

Not applicable.

\section{Competing interests}

All data related to this research has been included in the supplementary materials. 
477 Author details

$478 \mathrm{Lu} \mathrm{Luo}^{1 \dagger}$, Bo Wang ${ }^{2 \dagger}$, Jingwen Jiang ${ }^{3}$, Qin Huang ${ }^{1}$, Zheng Yu ${ }^{4}$, Hui Li ${ }^{5}$, Jiqing Zhang ${ }^{1}$, Chenyuyan

479 Yang $^{6}$, Hui Zhang ${ }^{7}$, Linlin Dong ${ }^{1 *}$, Shilin Chen ${ }^{1 *}$

480 Lu Luo ${ }^{1 \dagger}$ : sugarfhx@126.com;

481 Bo Wang ${ }^{2 \dagger}$ : wang_bo1986@hotmail.com;

482 Jingwen Jiang ${ }^{3}$ : jiangjingwen $@$,wchscu.cn;

483 Qin Huang1: 2119443480@qq.com;

484 Zheng Yu ${ }^{4}$ yuzhengyz@163.com;

485 Hui Li ${ }^{5}$ : tggzlda2017@163.com;

486 Jiqing Zhang1: 153696171@qq.com;

487 Chenyuyan Yang ${ }^{6}$ : yangchenyuyan@126.com;

488 Hui Zhang ${ }^{7}$ : hui@zhang.ac;

489 Linlin Dong ${ }^{1 *}$ : lldong@icmm.ac.cn;

490 Shilin Chen ${ }^{1 *}$ : slchen@icmm.ac.cn.

$491{ }^{1}$ Institute of Chinese Materia Medica, China Academy of Chinese Medical Sciences, Beijing 100700,

492 China

$493{ }^{2}$ Hubei Institute for Drug Control, Wuhan 430012, China

$494{ }^{3}$ West China Biomedical Big Data Center, West China Hospital, Sichuan University, Chengdu 610041, 495 China

$496{ }^{4}$ College of Medical Information and Engineering, Chengdu University of Traditional Chinese Medicine, 
${ }^{5}$ Institute of Botany, Chinese Academy of Sciences, Beijing 100093, China

${ }^{6}$ Institute of Medical Information, Chinese Academy of Medical Sciences \& Peking Union Medical

College, Beijing 100020, China

${ }^{7}$ Akupunktur Akademiet, Aabyhoej 8230, Denmark

$\mathrm{Lu} \mathrm{Luo}^{\dagger}$ and Bo Wang ${ }^{\dagger}$ contributed equally to this work.

\section{References}

1. Maiga A, Diallo D, Bye R, et al. Determination of Some Toxic and Essential Metal Ions in Medicinal and Edible Plants from Mali. J Agr Food Chem 2005, 53: 2316-2321.

2. Kim HS, Seo BH, Bae JS, et al. An integrated approach to safer plant production on metal contaminated soils using species selection and chemical immobilization. Ecotox Environ Safe 2016, 131:89-95.

3. Ministry of Science and Technology, China. http://www.most.gov.cn/ztzl/kxydfyyq/gzdt/202002/t20200218_151670.htm. press conference of Joint Prevention and Control of Epidemic Situation, 2020. (Accessed Feb 20, 2020)

4. Awodele O, Popoola TD, Amadi KC, et al. Traditional medicinal plants in Nigeria-Remedies or risks. Journal of Ethnopharmacology 2013, 150: 614-618.

5. Shaban N.S., Abdou K.A., Hassan E.H.Y. Impact of toxic heavy metals and pesticide residues in herbal products. Beni Suef Uni J Bas App Sci 2016:S2314853515000621. doi: 10.1016/j.bjbas.2015.10.001

6. Harris ESJ, Cao S, Littlefield BA, et al. Heavy metal and pesticide content in commonly prescribed individual raw Chinese Herbal Medicines. Sci Total Environ 2011, 409: 4297-4305. 
7. Mahurpawar M. Effects of heavy metals on human health. International journal of Treatment of Diabetes, Malaria and Pneumonia in Kisii Region, Southwest Kenya. Global Journal of Pharmacology 2012, 6: 245-251, 2012.

9. Li X, Chi W, Tian H, et al. Probabilistic ecological risk assessment of heavy metals in western

527

528

Laizhou Bay, Shandong Province, China. PLoS ONE 2018, 14: e0213011. https://doi.org/10.1371/journal.pone.0213011

10. Singh, NK, Raghubanshi As, Upadhyay AK, et al. Arsenic and other heavy metal accumulation in plants and algae growing naturally in contaminated area of West Bengal, India. Ecotox Environ Saf 2016, 130: 224-232.

11. Behnam A, Ghorbanpour M, Nikabadi S. Heavy metals in contaminated environment: Destiny of secondary metabolite biosynthesis, oxidative status and phytoextraction in medicinal plants. Ecotox Environ Safe 2017, 145: 377-390.

12. Abou A. A. K., Abou Donia M.A. Heavy Metals in Egyptian Spices and Medicinal Plants and the Effect of Processing on Their Levels. J Agr Food Chem 2000, 48: 2300-2304.

13. Mulaudzi RB, Tshikalange TE, Olowoyo JO et al., Antimicrobial activity, cytotoxicity evaluation and heavy metal content of five commonly used South African herbal mixtures. S Afr J Bot 2017, 112: 314-318.

14. Leal AS, Prado G, Gomes TCB, et al. Determination of metals in medicinal plants highly consumed in Brazil. Braz J Pharm Sci 2013, 499: 599-607. 
542

543

544

545

546

547

548

549

550

551

552

553

554

555

556

557

558

559

560

561

562

563

15. Broadway A, Cave MR, Wragg J, et al. Determination of the bioaccessibility of chromium in Glasgow soil and the implications for human health risk assessment. Sci Total Environ 2010, 409: $267-277$.

16. Wei, J., Cen, K. Content and dietary exposure of cadmium among residents in Northeast China: a case study based on the 5th China Total Diet Study. Environ Sci Pollut Res 2020. https://doi.org/10.1007/s11356-019-07016-7

17. National Pharmacopoeia Commission. Pharmacopoeia of the People's Republic of China, Part IV. Beijing, China: China Medical Science Press; 2020.

18. Pohl, Pawel, et al. The determination of elements in herbal teas and medicinal plant formulations and their tisanes. J pharmaceut biomed, 2016, 130:326.

19. Wang J, Hansen EH. Online-Sample Pretreatment Schemes for Trace-Level Determinations of Metals by Coupling Flow Injection or Sequential Injection with ICP-MS. ChemInform 2004, 35:836-846.

20. Pereira J, Moraes D, Antes F., et al. Determination of metals and metalloids in light and heavy crude oil by ICP-MS after digestion by microwave-induced combustion. Microchem J 2010, 96:4-11.

21. Gonzalez-Martin MI, Revilla L, Betances-Salcedo EV, et al. Pesticide residues and heavy metals in commercially processed propolis. Microchem J 2018: S0026265X18305800-.

22. Wang J, Chen X, Shi Y, et al. Evaluation of heavy metal accumulation in greenhouse soils in Shenyang, Northeast China. Proceedings of SPIE - The International Society for Optical Engineering, 2009, 7491:26

23. Sawut R, Kasim N, Maihemuti B et al. Pollution characteristics and health risk assessment of 
564

565

566

567

568

569

570

571

572

573

574

575

576

577

578

579

580

581

582

583

584

585

heavy metals in the vegetable bases of northwest China. Sci Total Environ 2018, 642: 864-878.

24. Zhao Q, Hao L J, Ma X L, et al. Sduty on thin layer chromatography differentiation and determination of six kinds of prepared Bombyx batryticatus. Liaoning J Trad Chin Med 2010, 37 :

2421-2424.

25. Zuo TT, Wang Y, Zhang L, et al. Guideline of risk assessment of exogenous harmful residues in traditional Chinese medicines. Chin J Pharm Anal 2019, 39: 1902-7. DOI:10.1615LI Xin-yue1, KONG Dan-dan2.

26. Li X, Kong D, Wang R, et al. Safety evaluation of heavy metals contaminated Xiaochaihu Tang using health risk. Chin J Chin Mat Med 2019, https://doi.org/10.19540/j.cnki.cjcmm.20191015.201.

27. Chen Y, Sun S, Duan X et al. Refined Assessment of Exposure and Health Risks of Heavy Metals in Water for the Children in Xigu District, Lanzhou. Environ Sci 2019, 10.13227/j.hjkx.201904229.

28. Asgari Lajayer B, Ghorbanpour M, Nikabadi S. Heavy metals in contaminated environment: Destiny of secondary metabolite biosynthesis, oxidative status and phytoextraction in medicinal plants. Ecotox Environ Safe 2017, 145: 377-390.

29. Alidadi H, Sany S, Oftadeh B, et al. Health risk assessments of arsenic and toxic heavy metal exposure in drinking water in northeast Iran. Environ Health Prev Med 2019, 24:1. DOI: 10.1186/s12199-019-0812-X.

30. Kofi A, Dickson R, Amponsah I, et al. The heavy metal contents of some selected medicinal plants sampled from different geographical locations. Phcog Res 2013, 5:103.

31. Ernst E. Heavy metals in traditional Indian remedies. Eur J Clin Pharmacol 2002, 57:891-896. 
586

587

588

589

590

591

592

593

594

595

596

597

598

599

600

601

602

603

604

605

606

607

32. Obi E, Akunyili DN, Ekpo B, et al. Heavy metal hazards of Nigerian herbal remedies. Sci Total Enviro 2006, 369:35-41.

33. Ren W, Geng Y, Ma Z, et al. Reconsidering brownfield redevelopment strategy in China's old industrial zone: a health risk assessment of heavy metal contamination. Environ Sci \& Pollut Res $2015,22: 2765-2775$.

34. Huang Y, Ying T, Zhang N, et al. Human health risk assessment of heavy metals in the soilPanax notoginseng system in Yunnan province, China. Hum Ecol Risk Assess 2018, 18 : $1312-1326$.

35. Bolan S, Kunhikrishnan A, Seshadri B, et al. Sources, distribution, bioavailability, toxicity, and risk assessment of heavy metal(loid)s in complementary medicines. Enviro Inter 2017; 108:103-118.

36. Lee SD, Lee YK, Kim MS, et al. The Content and Risk Assessment of Heavy Metals in Herbal Pills. J Food Safety 2012, 27:4.

37. Ghasemidehkordi B, Malekirad AA, Nazem H, et al. Concentration of lead and mercury in collected vegetables and herbs from Markazi province, Iran: a non-carcinogenic risk assessment. Food ChemToxicol 2018, 113:204-210.

38. Oliveira LMD, Das S, Silva EBD, et al. Metal concentrations in traditional and herbal teas and their potential risks to human health. Sci Total Environ 2018, 633: 649-657.

39. Street RA. Heavy metals in medicinal plant products - An African perspective. S Afr J Bot 2012, 82: 67-74.

40. Khan MA, Wajid A, Noor S. Effect of soil contamination on some heavy metals content of cannais sativab. J Chem Soc Pakistan 2008, 30: 805-809. 
608

609

610

611

612

613

614

615

616

617

618

619

620

621

622

623

41. Rong Z, Hui-Xia Y, Jin P U, et al. Research Status of Heavy Metal Pollution and Evaluation Methods of Traditional Chinese Medicine. Chin J Info Tradit Chin Med 2016, 23: 134-136.

42. Rehman MZU, Rizwan M, Ali S, et al. Remediation of heavy metal contaminated soils by using, Sandilyan S, Kathiresan K. Decline of mangroves - A threat of heavy metal poisoning in Asia. Ocean Coast Manage 2014, 102:161-168.

43. Augustina $P$, Adriana M. Phytoremediation using medicinal plants - a review. Annals of the University of Craiova - Agriculture, Montanology, Cadastre Series 2014, 2014: 186-193.

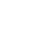

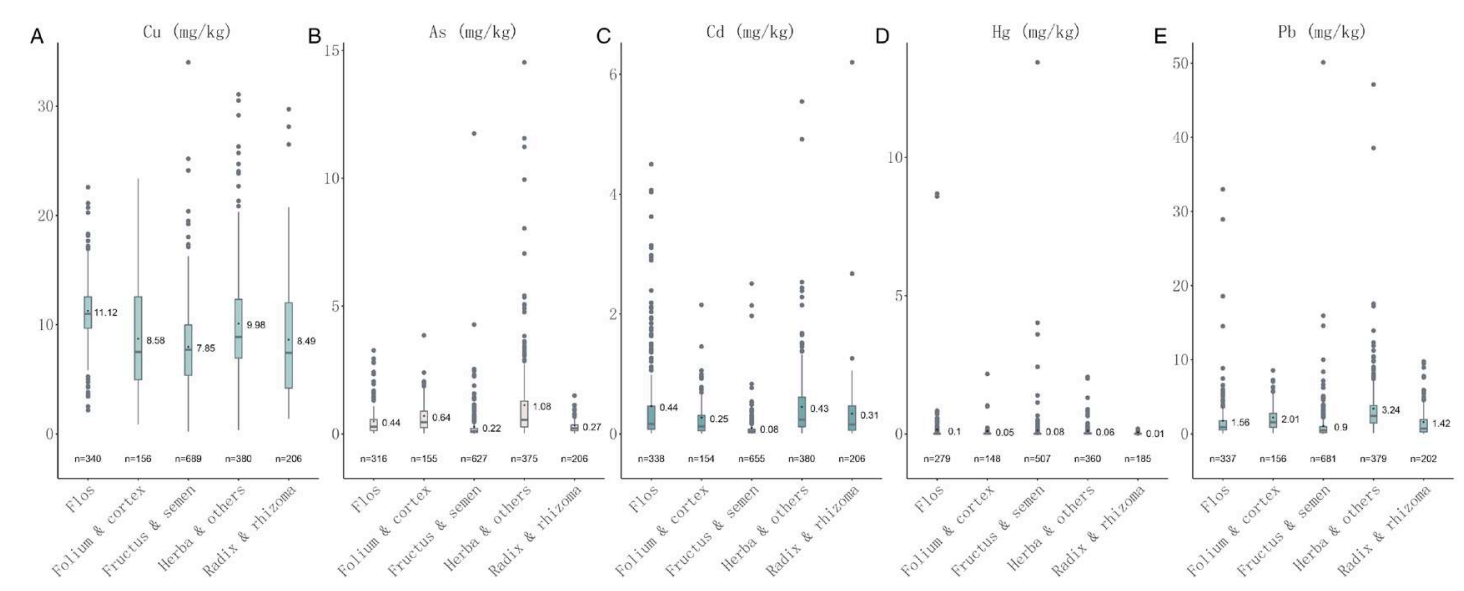

Fig.1. Plotbox showing concentrations of five heavy metals in five medicinal properties. (A)

Concentrations of $\mathrm{Cu}$ in five medicinal properties. (B) Concentrations of $\mathrm{As}$ in five medicinal properties. (C) Concentrations of $\mathrm{Cd}$ in five medicinal properties. (D) Concentrations of $\mathrm{Hg}$ in five medicinal properties. (E) Concentrations of $\mathrm{Pb}$ in five medicinal properties. 


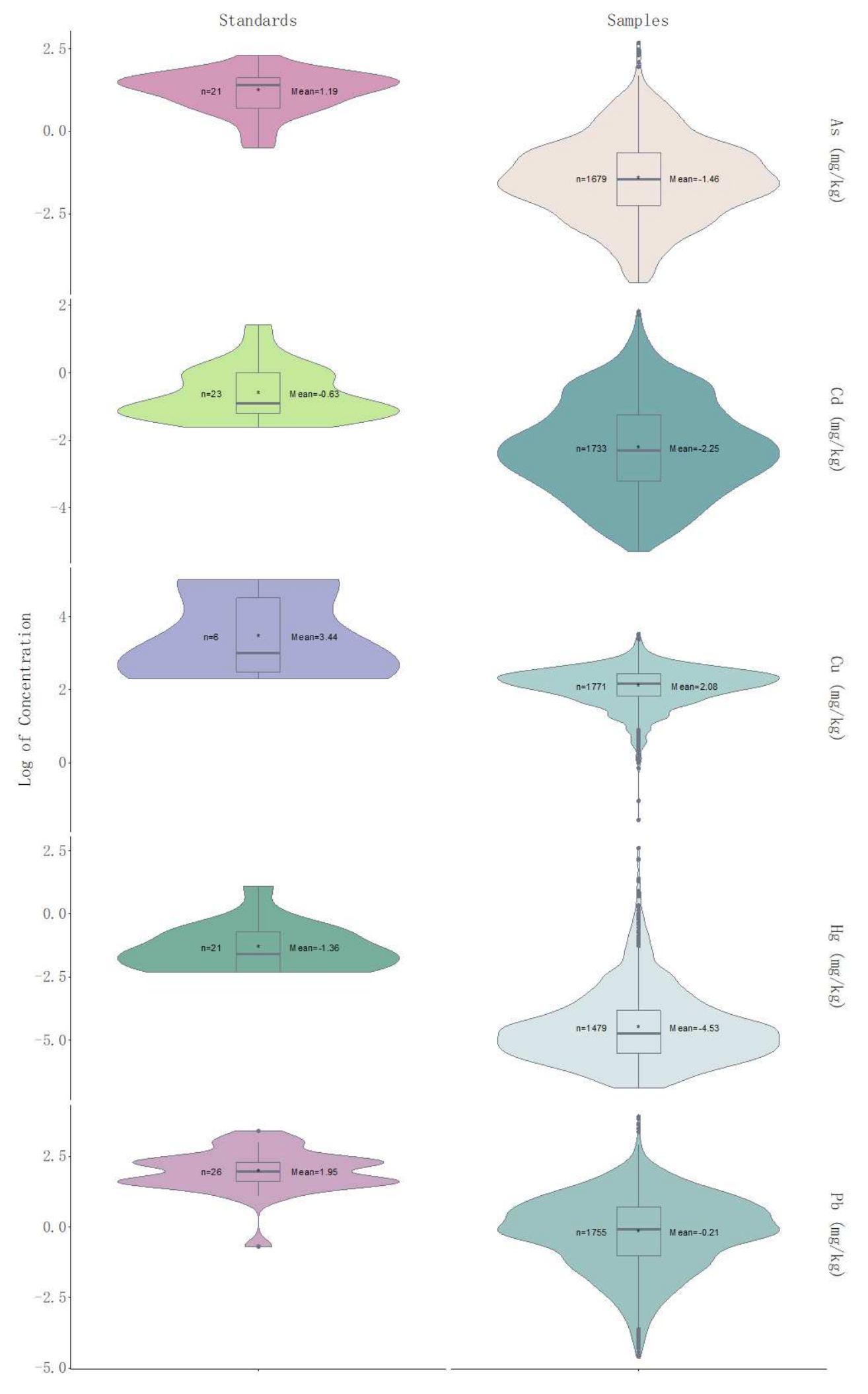

624

625 Fig.2. Violin plot showing $\log _{2}$ (concentration) values of five heavy metals in 1773 samples and

626 permissible limits in different countries of each heavy metal (see Table S2 for detailed standards of

627 each heavy metal). 

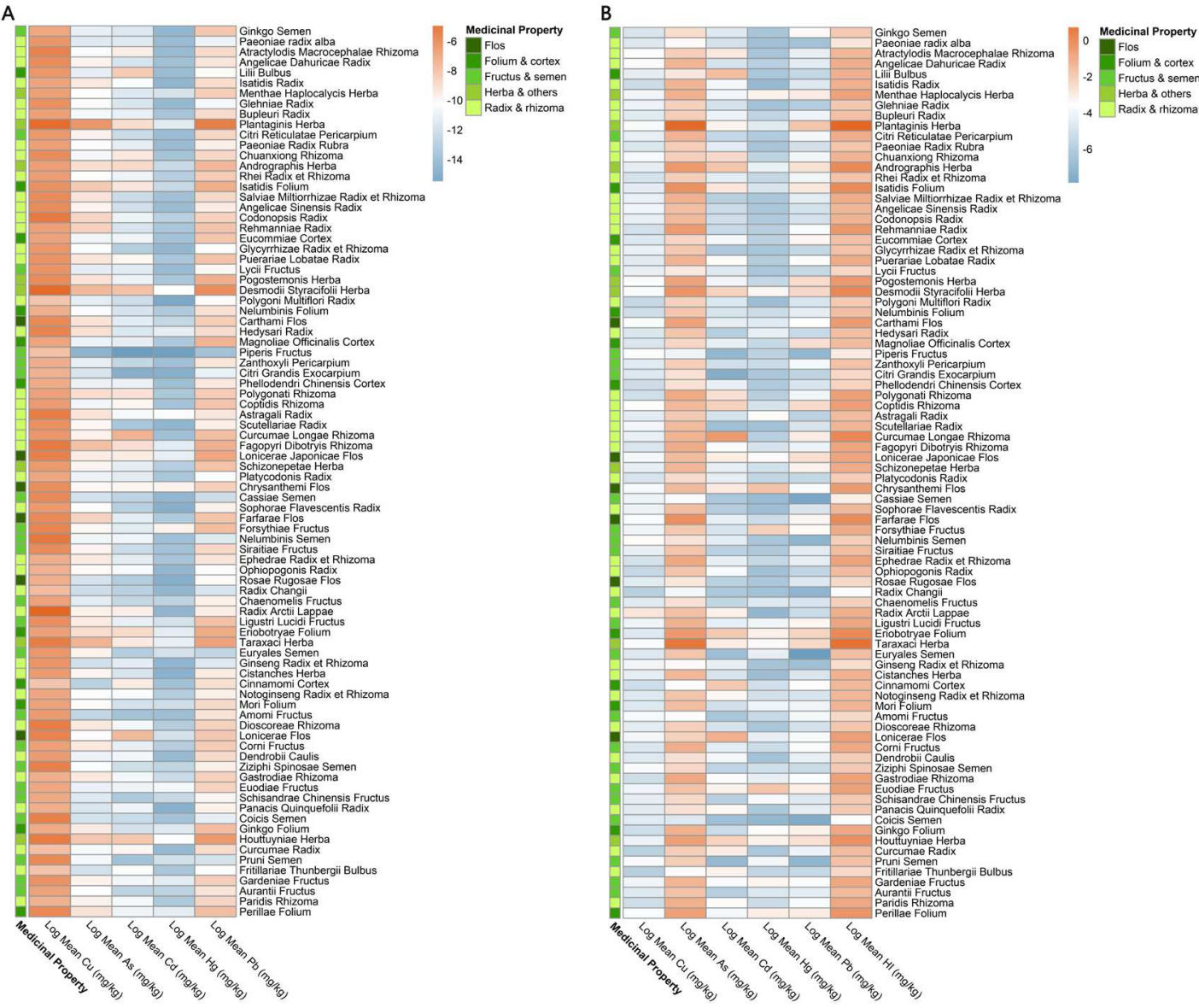

630 Fig.3. Heatmap of EDI and HI by mean concentrations detected for five heavy metals in 86 kinds of

631 herbal medicines (A) Heatmap showing $\log _{2}$ (Estimated Daily Intake, EDI) values by mean

632 concentrations detected of five heavy metals in 86 herbal medicines; (B) Heatmap showing $\log _{2}$

633 (Hazard Index, HI) values by mean concentrations detected of five heavy metals in 86 herbal 634 medicines. 

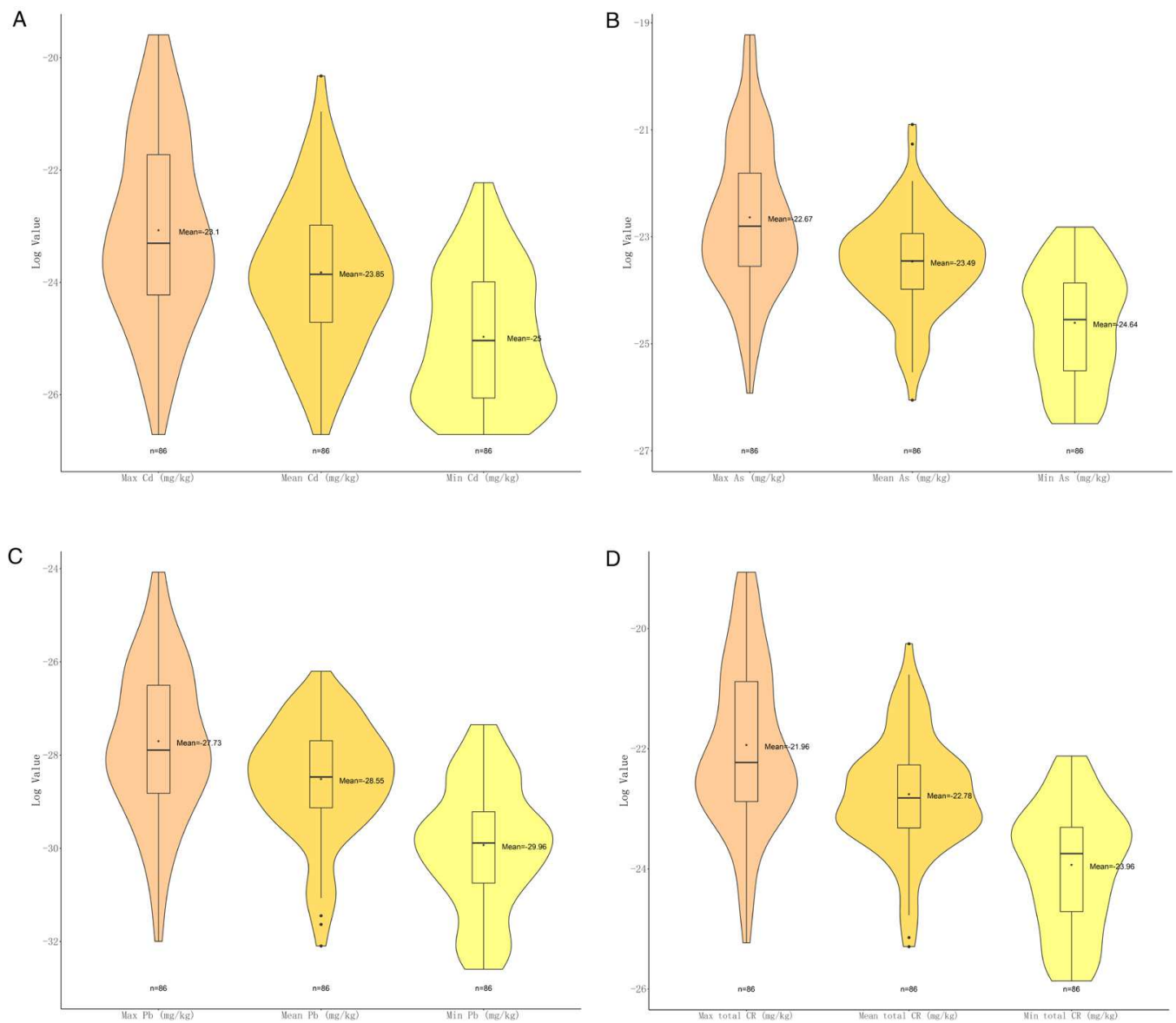

637 Fig.4. Violin plot of carcinogenic risk (CR) of three carcinogenic metals with maximal, minimal and mean concentrations detected

639 (A) Violin plot showing $\log _{2}(\mathrm{CR})$ values of Cd with maximal, minimal and mean concentrations; (B)

640 Violin plot showing $\log _{2}(\mathrm{CR})$ values of As with maximal, minimal and mean concentrations; (C)

641 Violin plot showing $\log _{2}(\mathrm{CR})$ values of $\mathrm{Pb}$ with maximal, minimal and mean concentrations; (D)

642 Violin plot showing total $\log _{2}(\mathrm{CR})$ values with maximal, minimal and mean concentrations. 


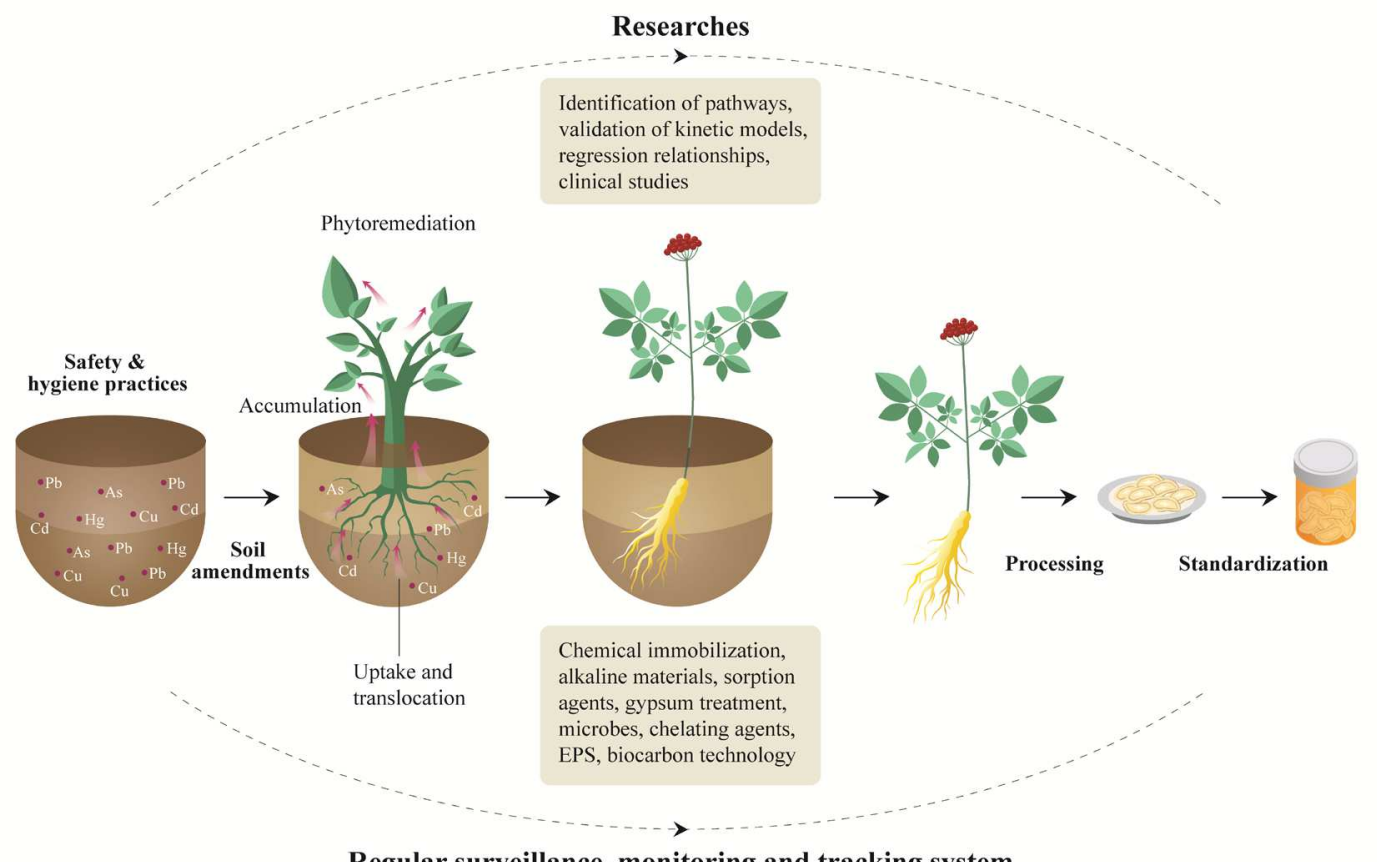

Regular surveillance, monitoring and tracking system

644

645 Fig.5. From-cradle-to-grave heavy metal control strategy of herbal medicine production

646

647

Table 1 Contents and detection rates of five heavy metals in herbal medicines

648

\begin{tabular}{|c|c|c|c|c|c|c|}
\hline \multicolumn{2}{|l|}{ Heavy metals } & $\mathrm{Cu}\left(\mathrm{mg} \cdot \mathrm{kg}^{-1}\right)$ & $\operatorname{As}\left(\mathrm{mg} \cdot \mathrm{kg}^{-1}\right)$ & $\mathrm{Cd}\left(\mathrm{mg} \cdot \mathrm{kg}^{-1}\right)$ & $\mathrm{Hg}\left(\mathrm{mg} \cdot \mathrm{kg}^{-1}\right)$ & $\mathrm{Pb}\left(\mathrm{mg} \cdot \mathrm{kg}^{-1}\right)$ \\
\hline \multirow{3}{*}{ Concentrations } & Mean \pm SD & $9.07 \pm 4.21$ & $0.50 \pm 0.93$ & $0.27 \pm 0.48$ & $0.07 \pm 0.51$ & $1.69 \pm 2.85$ \\
\hline & Max & 34.01 & 14.53 & 6.20 & 13.43 & 50.11 \\
\hline & $75^{\text {th }}$ percentile & 11.39 & 0.52 & 0.29 & 0.02 & 2.02 \\
\hline \multirow{3}{*}{ metal } & Median & 8.78 & 0.23 & 0.10 & 0.01 & 0.92 \\
\hline & $25^{\text {th }}$ percentile & 6.17 & 0.11 & 0.04 & 0.004 & 0.36 \\
\hline & Min & 0.21 & 0.01 & 0.01 & 0.001 & 0.01 \\
\hline Mean & Flos $(\mathrm{n}=340)$ & $11.12 \pm 2.73$ & $0.4 \pm 0.49$ & $0.439 \pm 0.686$ & $0.081 \pm 0.667$ & $1.55 \pm 2.8327$ \\
\hline
\end{tabular}




\begin{tabular}{|c|c|c|c|c|c|c|}
\hline $\begin{array}{l}\text { concentrations of } \\
\text { five medicinal } \\
\text { plant properties }\end{array}$ & $\begin{array}{l}\text { Folium \& } \\
\text { cortex } \\
(n=157)\end{array}$ & $8.52 \pm 4.73$ & $0.64 \pm 0.57$ & $0.244 \pm 0.307$ & $0.049 \pm 0.206$ & $1.99 \pm 1.6128$ \\
\hline \multirow{3}{*}{ plant properties } & $\begin{array}{l}\text { Fructus } \& \\
\text { semen } \\
(n=689)\end{array}$ & $7.85 \pm 3.64$ & $0.2 \pm 0.55$ & $0.07 \pm 0.18$ & $0.08 \pm 0.57$ & $0.89 \pm 2.28$ \\
\hline & $\begin{array}{l}\text { Herba \& } \\
\text { others } \\
(\mathrm{n}=\mathbf{3 8 0})\end{array}$ & $9.98 \pm 4.53$ & $1.06 \pm 1.56$ & $0.43 \pm 0.54$ & $0.06 \pm 0.19$ & $3.23 \pm 3.83$ \\
\hline & $\begin{array}{l}\text { Radix } \& \\
\text { rhizoma } \\
(n=207)\end{array}$ & $8.45 \pm 5.26$ & $0.27 \pm 0.22$ & $0.31 \pm 0.52$ & $0.01 \pm 0.02$ & $1.38 \pm 1.74$ \\
\hline \multicolumn{2}{|l|}{ Detection rates } & $99.89 \%$ & $94.70 \%$ & $97.74 \%$ & $84.43 \%$ & $98.98 \%$ \\
\hline \multirow{3}{*}{\multicolumn{2}{|c|}{ Top five herbal medicines with }} & $\begin{array}{l}\text { Schisandrae } \\
\text { Chinensis } \\
\text { Fructus } \\
(34.01)\end{array}$ & $\begin{array}{l}\text { Plantaginis Herba } \\
(14.53)\end{array}$ & $\begin{array}{l}\text { Curcumae Longae } \\
\text { Rhizoma } \\
(6.20)\end{array}$ & $\begin{array}{l}\text { Chrysanthemi Flos } \\
(8.69)\end{array}$ & $\begin{array}{l}\text { Euodiae Fructus } \\
(50.11)\end{array}$ \\
\hline & & $\begin{array}{l}\text { Plantaginis } \\
\text { Herba } \\
(31.08)\end{array}$ & $\begin{array}{l}\text { Corni Fructus } \\
(11.75)\end{array}$ & $\begin{array}{l}\text { Andrographis Herba } \\
(5.55)\end{array}$ & $\begin{array}{l}\text { Chrysanthemi Flos } \\
(8.58)\end{array}$ & $\begin{array}{l}\text { Plantaginis } \\
\text { Herba } \\
(47.12)\end{array}$ \\
\hline & & $\begin{array}{l}\text { Taraxaci Herba } \\
(30.52)\end{array}$ & $\begin{array}{l}\text { Plantaginis Herba } \\
(11.57)\end{array}$ & $\begin{array}{l}\text { Houttuyniae Herba } \\
(4.92)\end{array}$ & $\begin{array}{l}\text { Forsythiae Fructus } \\
(4.02)\end{array}$ & $\begin{array}{l}\text { Plantaginis } \\
\text { Herba }\end{array}$ \\
\hline
\end{tabular}




\begin{tabular}{|l|l|l|l|l|}
\hline Radix Arctii & & & & $(38.56)$ \\
\hline Lappae & Plantaginis Herba & Lonicerae Flos & Forsythiae Fructus & Lonicerae \\
\hline (29.73) & (11.23) & $(4.50)$ & $(3.60)$ & Japonicae Flos \\
\hline Taraxaci Herba & Taraxaci Herba & Lonicerae Flos & Gardeniae Fructus & Lonicerae \\
(29.18) & (9.95) & $(4.07)$ & $(2.42)$ & Japonicae Flos \\
\hline
\end{tabular}

649

Table 2 Health risk assessment scores of top risk-inducing herbal medicines

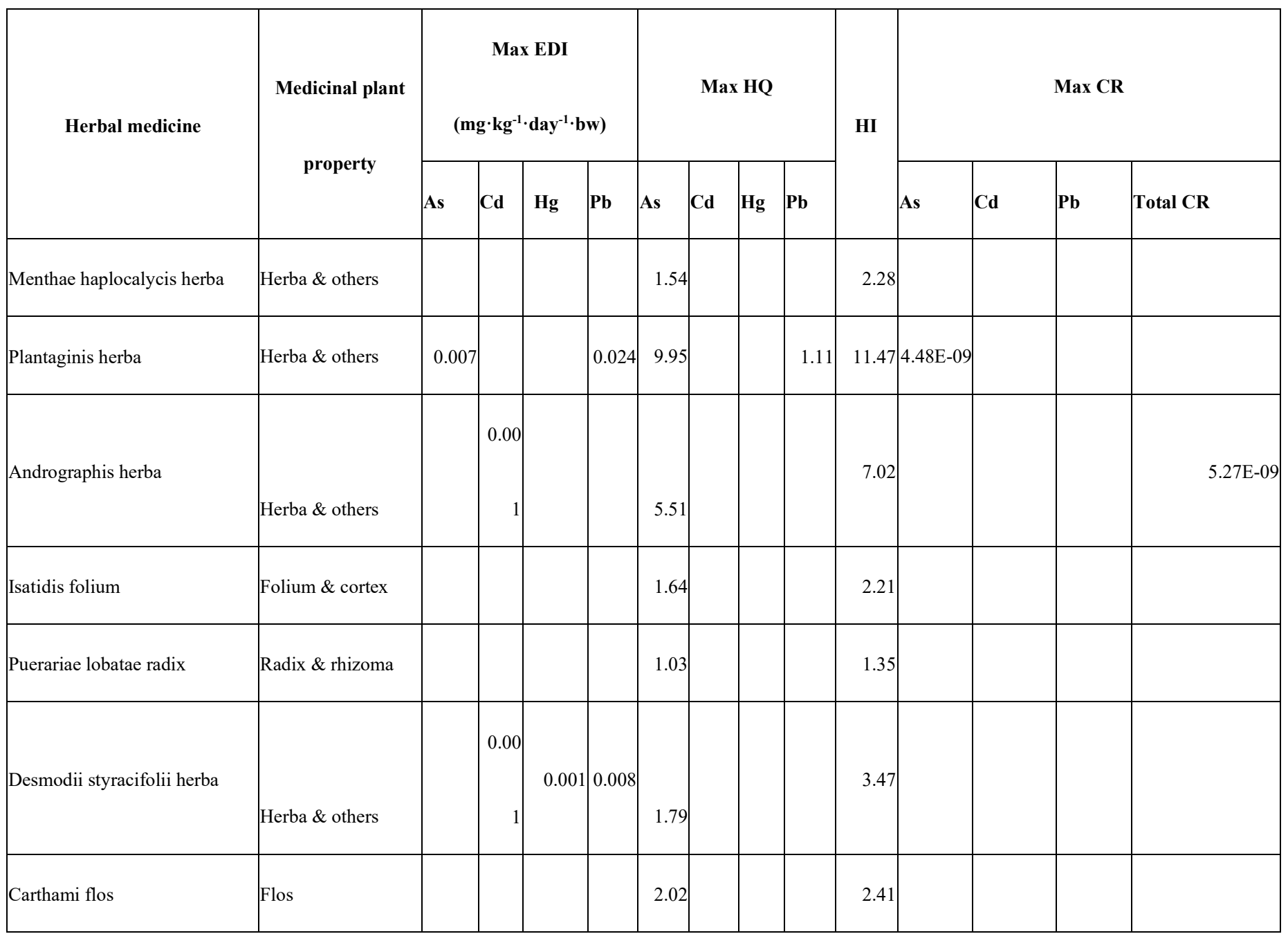




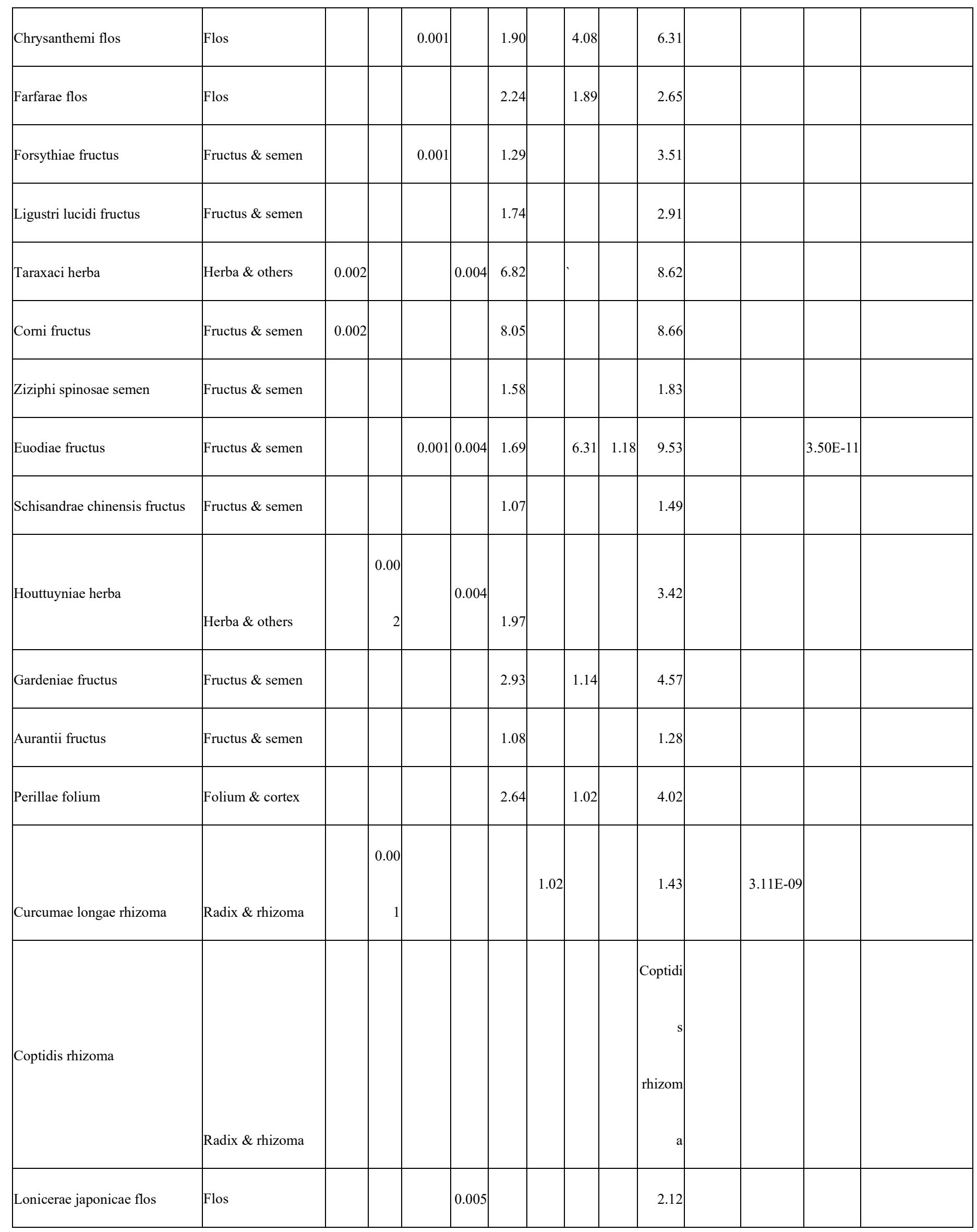




\begin{tabular}{|l|l|l|l|l|l|l|l|l|l|l|l|l|l|l|}
\hline Chaenomelis fructus & Fructus \& semen & & & & & & & & & 1.48 & & & \\
\hline Lonicerae flos & & & 0.00 & & & & & & & & & & \\
& Flos & & 1 & & & & & & & & \\
\hline
\end{tabular}

651 The estimated daily intakes (EDI, $\left.\mathrm{mg} \cdot \mathrm{kg}^{-1} \cdot \mathrm{day}^{-1} \cdot \mathrm{bw}\right)$ above their corresponding provisional tolerable daily intakes (PTDI) were

652 shown (The PTDIs $\left(\mathrm{mg} \cdot \mathrm{kg}^{-1} \cdot \mathrm{day}^{-1}\right.$ ) of $\mathrm{As}, \mathrm{Hg}, \mathrm{Pb}$, and $\mathrm{Cd}$ are $0.00214,0.00057,0.00357$, and 0.00083 , respectively). The

653 non-carcinogenic hazard quotient (HQ) and non-carcinogenic Hazard Index (HI) above one were shown. The carcinogenic risks

654 (CR) higher than $10^{-6}$, which means one case of cancer over one million exposed people, is considered unacceptable, thus shown

655 here. All scores in this table were calculated with maximal concentrations of each herbal medicine.

656 
Figures

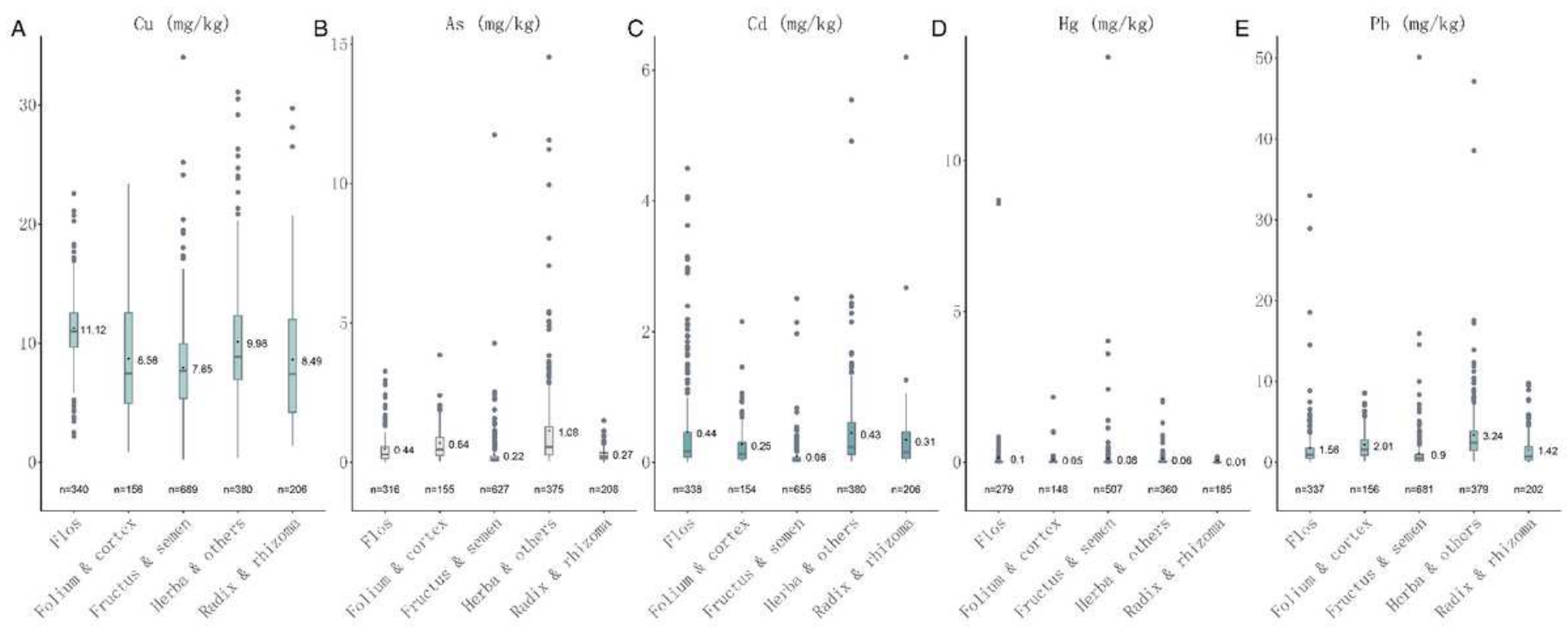

Figure 1

Plotbox showing concentrations of five heavy metals in five medicinal properties. (A) Concentrations of $\mathrm{Cu}$ in five medicinal properties. (B) Concentrations of As in five medicinal properties. (C) Concentrations of $\mathrm{Cd}$ in five medicinal properties. (D) Concentrations of $\mathrm{Hg}$ in five medicinal properties. (E) Concentrations of $\mathrm{Pb}$ in five medicinal properties. 


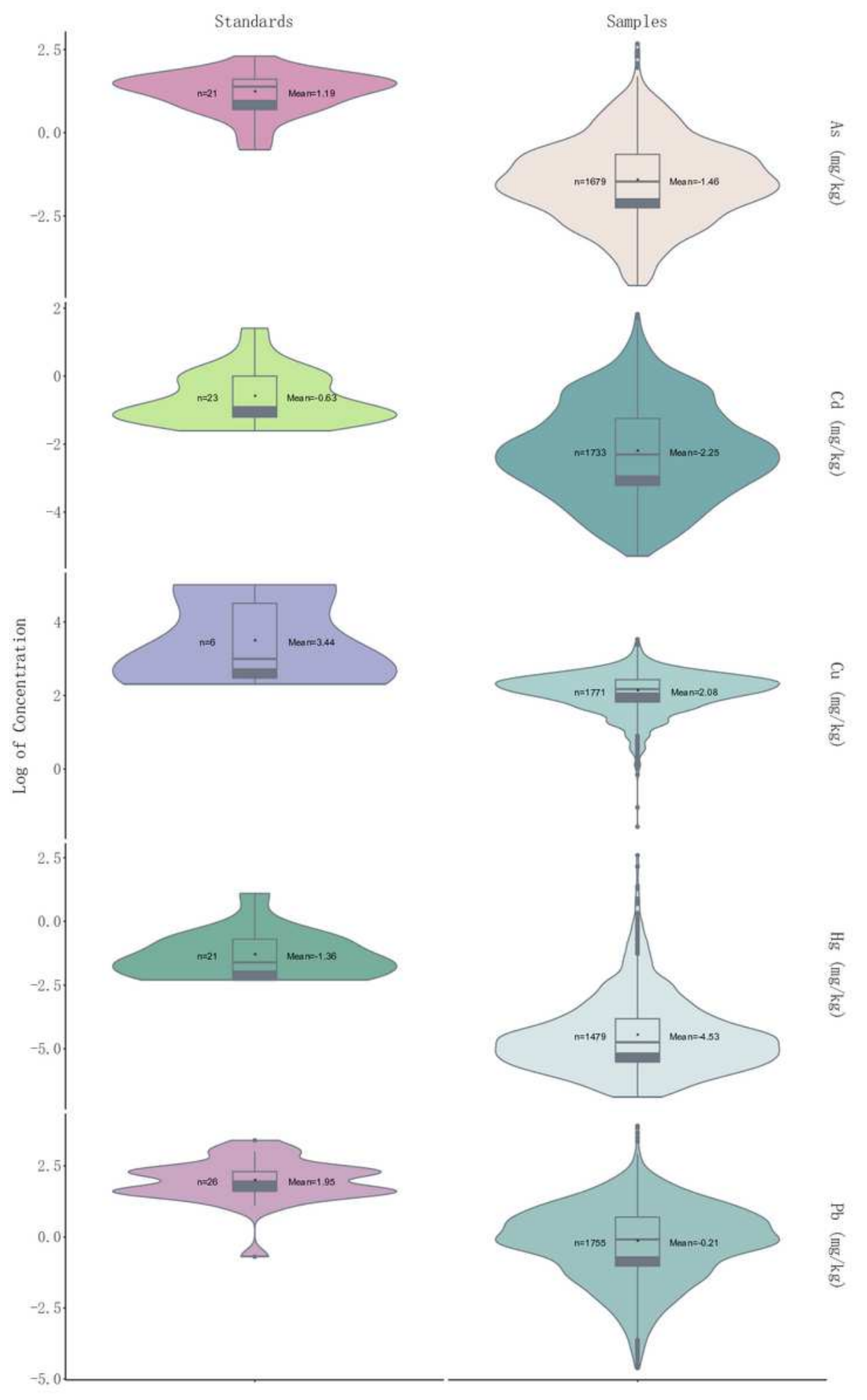

Figure 2

Violin plot showing log2 (concentration) values of five heavy metals in 1773 samples and permissible limits in different countries of each heavy metal (see Table $S 2$ for detailed standards of each heavy metal). 
A

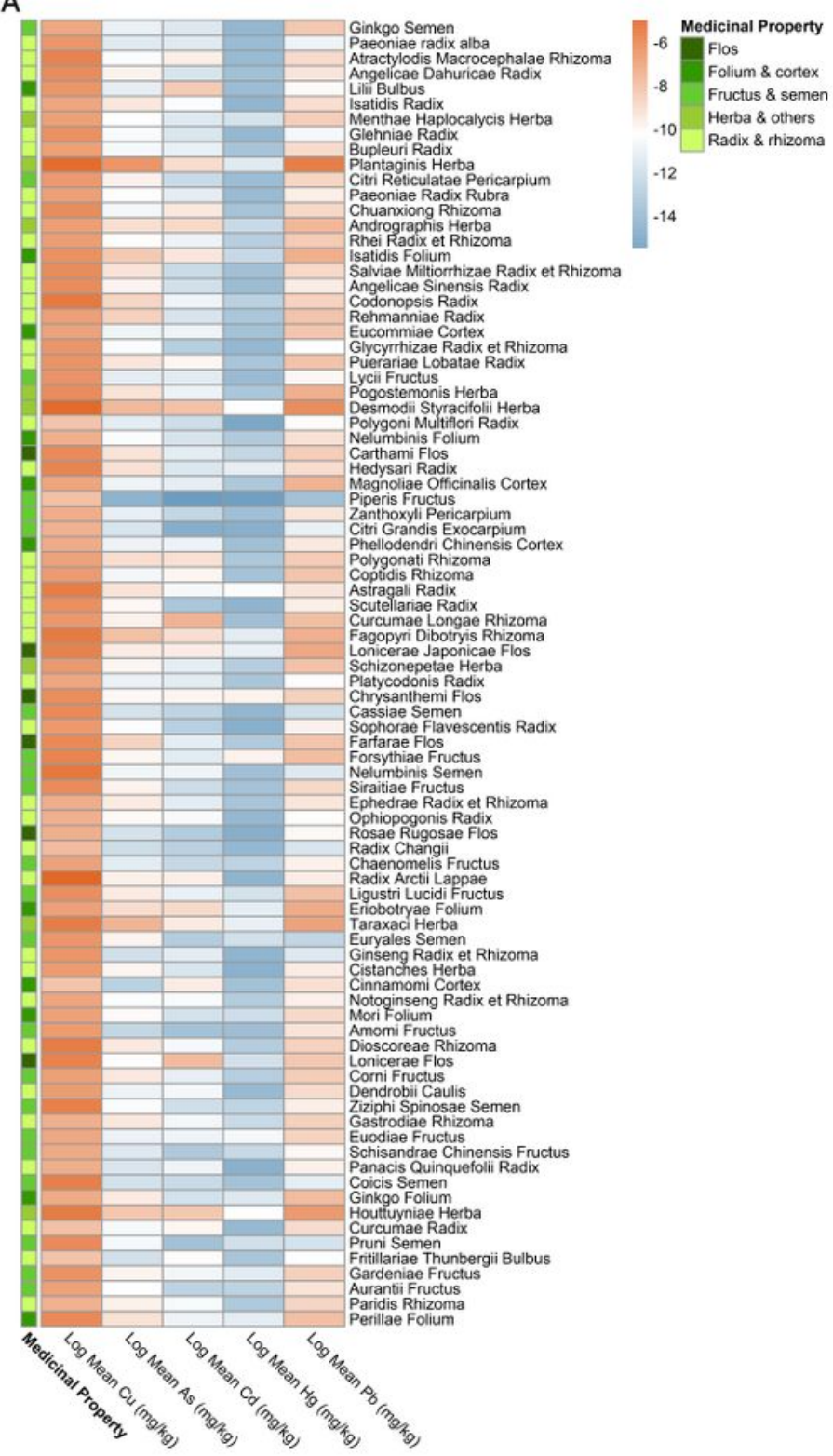

B

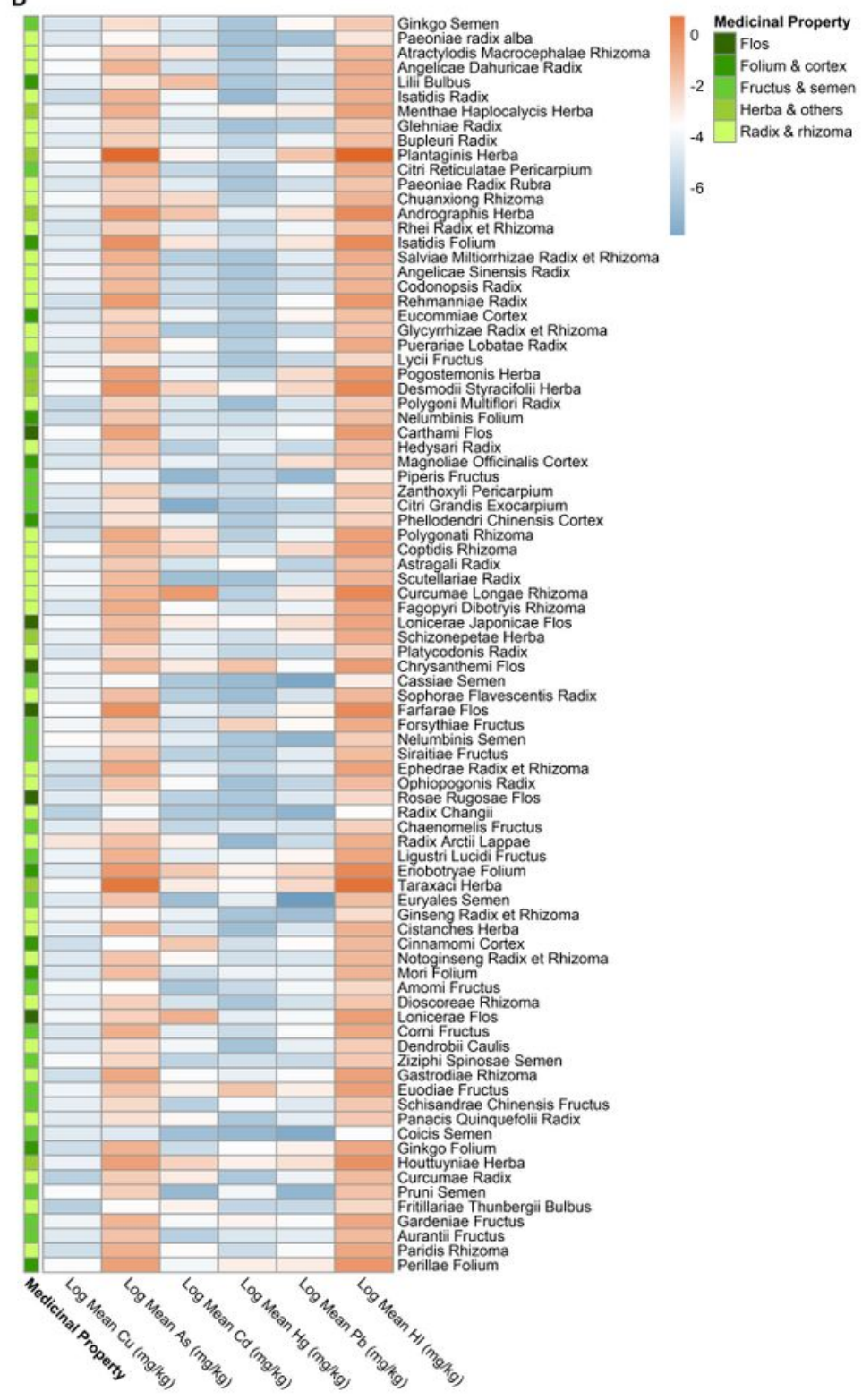

\section{Figure 3}

Heatmap of EDI and HI by mean concentrations detected for five heavy metals in 86 kinds of herbal medicines (A) Heatmap showing log2 (Estimated Daily Intake, EDI) values by mean concentrations detected of five heavy metals in 86 herbal medicines; (B) Heatmap showing log2 (Hazard Index, HI) values by mean concentrations detected of five heavy metals in 86 herbal medicines. 
A

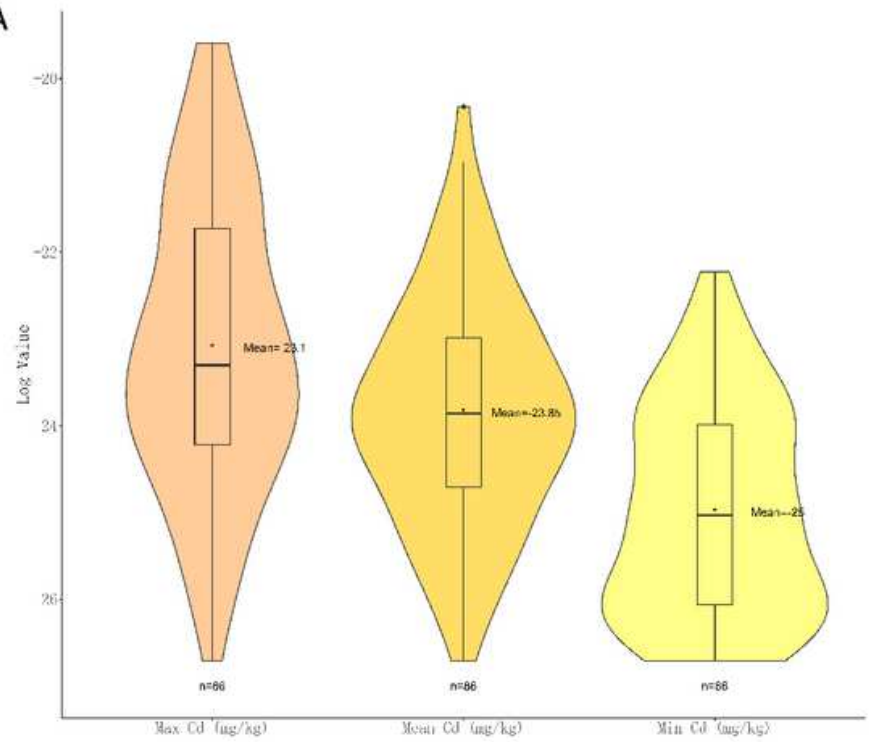

$\mathrm{C}$

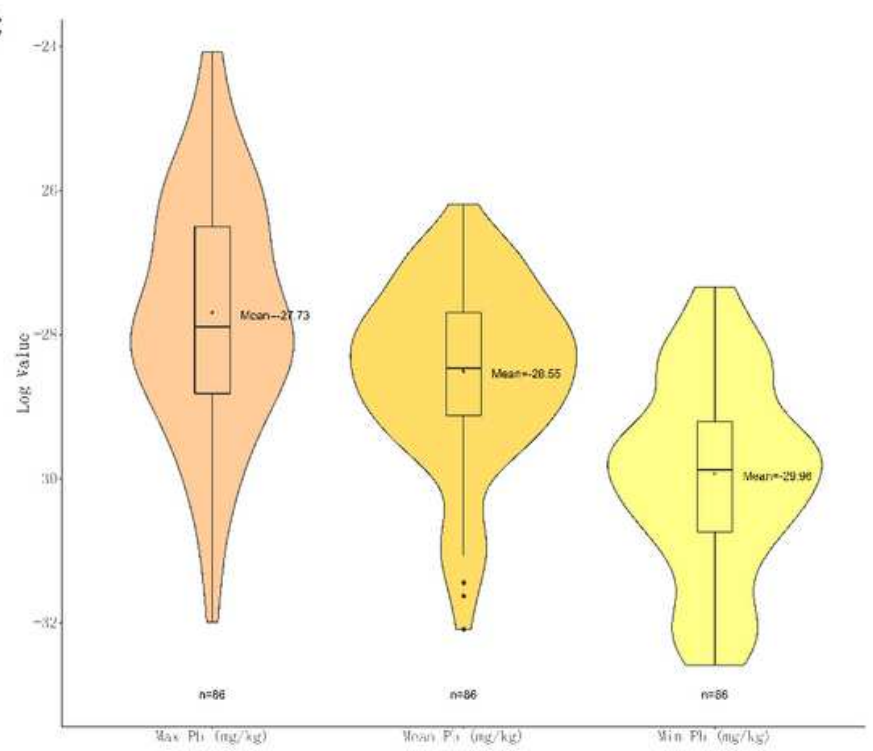

B

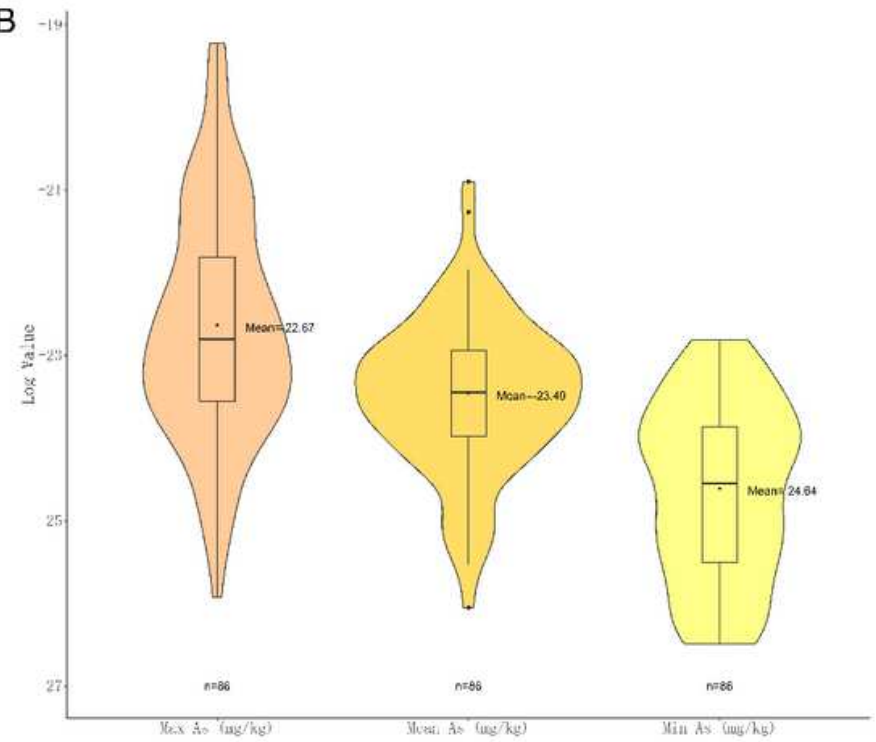

D

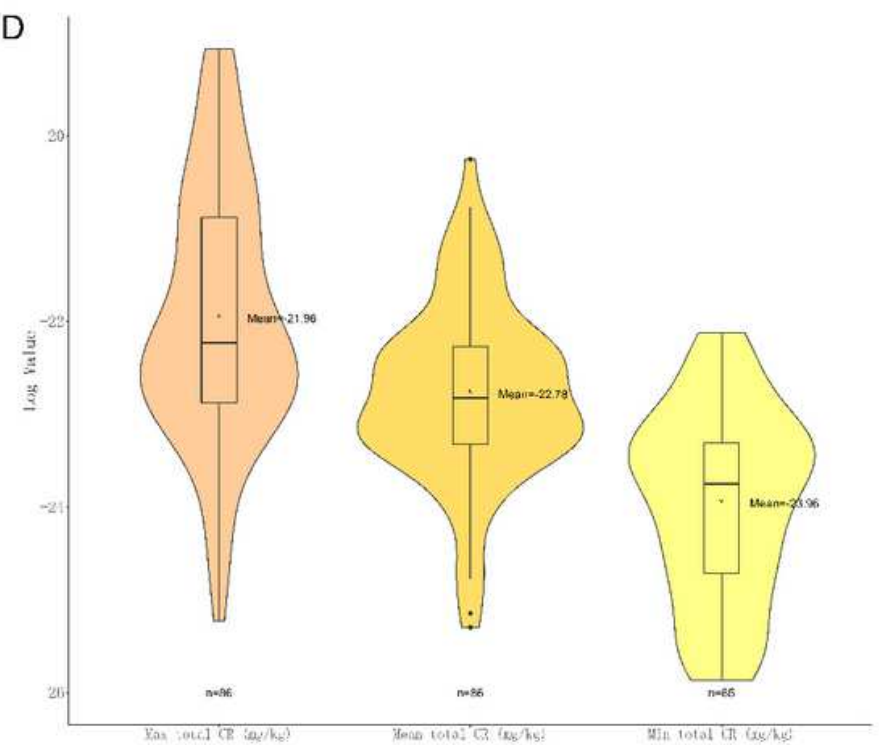

\section{Figure 4}

Violin plot of carcinogenic risk (CR) of three carcinogenic metals with maximal, minimal and mean concentrations detected (A) Violin plot showing log2 (CR) values of $\mathrm{Cd}$ with maximal, minimal and mean concentrations; (B) Violin plot showing log2 (CR) values of As with maximal, minimal and mean concentrations; (C) Violin plot showing log2 (CR) values of $\mathrm{Pb}$ with maximal, minimal and mean concentrations; (D) Violin plot showing total log2 (CR) values with maximal, minimal and mean concentrations. 


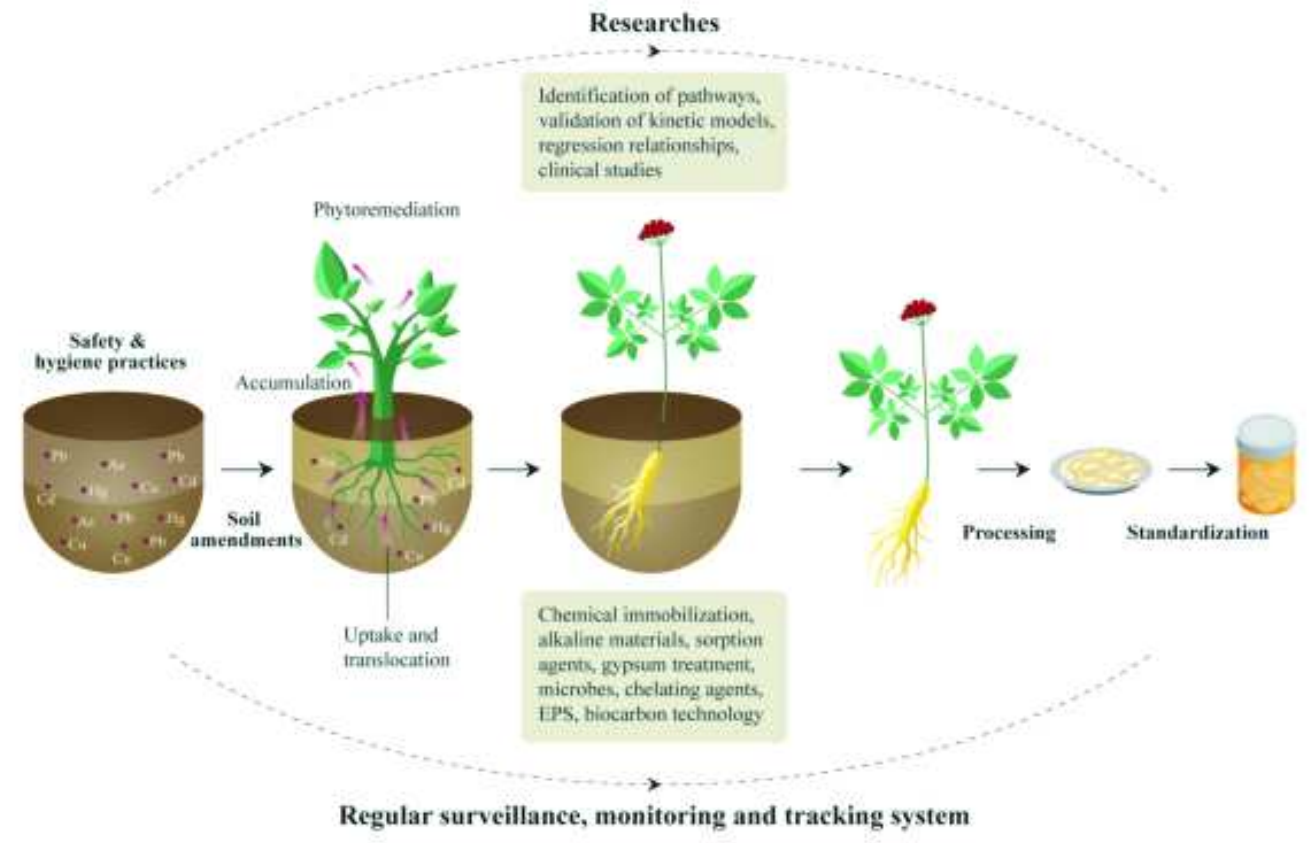

Figure 5

From-cradle-to-grave heavy metal control strategy of herbal medicine production

\section{Supplementary Files}

This is a list of supplementary files associated with this preprint. Click to download.

- GA.pdf

- GA.pdf

- Listofsamples.xlsx

- Listofsamples.xlsx

- Supplementarymaterials.docx

- Supplementarymaterials.docx 